\title{
Exchange Rate Appreciations, Labor Market Rigidities, and Informality
}

\author{
Norbert M. Fiess* \\ Marco Fugazza \\ William Maloney* \\ The World Bank
}

February 2002

\begin{abstract}
This paper works at the interface of the literature exploring the raison d'etre of the informal labor market and that explaining the real exchange rate appreciations occurring in many Latin American countries during periods of reform. We first build a small country-Australian style model where the informal sector is seen as an unregulated non-tradables sector, augmented by heterogeneity in entrepreneurial ability and capital adjustment costs. We then examine the behavior of the model with and without a formal sector rigidity. We show that the co-movements of relative formal/informal incomes, formal/informal sector size, and the real exchange rate can offer insight into the level of distortion in the labor market and the source of ER fluctuations. We then explore time series data from Brazil, Colombia and Mexico using multivariate co-integration techniques to establish what "regime" each country is in at various periods of time. Mexico, for instance, appears to be relative undistorted and the 1987-92 appreciation appears to be largely a function of a boom in the non-tradables sector rather than wage inertia. In spite of a secular expansion of the informal sector and there is little evidence of dualism or of a rigidity driven appreciation of the Real, from 1993-1996. Post 1995 Colombia corresponds to a classic segmented labor market and an appreciation partly driven by labor market rigidities. Graphical analysis suggests that neither the Argentine appreciation (1988-1992) or the celebrated Chilean appreciation (1975-1982) were driven by inertial forces.
\end{abstract}

\footnotetext{
- This work partially financed by the Regional Studies Program of the Office of the Chief Economist for Latin America and the Caribbean. The development of the conceptual framework was supported by the Franco-Italian Foundation for Theoretical Philanthropy. We are grateful to Rashmi Shankar for early conceptual discussions, to Leonardo Gaspirini for helpful comments, to Norman Loayza and Claudio Montenegro for help with data, and to Gabriel Montes for expert research assistance. Corresponding author:wmaloney@worldbank.org.

* The World bank

CERAS, Ecole Nationale des Ponts et Chaussées
} 


\section{Introduction}

This paper works at the interface of two literatures. The first debates whether the unregulated or informal self-employed sector that accounts for often over $30 \%$ of LDC labor forces should be seen as the disadvantaged segment of a highly segmented labor market, or perhaps simply as an unregulated, largely voluntary, entrepreneurial sector. The issue is particularly important in light of the rise in the importance of the sector in the 1990s. The second literature debates whether the sources of the real exchange rate appreciations that were observed in the 1980 and 90s in many countries of Latin America were due to inertial considerations, such as backward indexation to inflation, or to "real" effects such as productivity shocks or booms in non-tradable demand. The first question we propose can be answered by looking at the time series properties of relative sector sizes and relative remuneration of the formal salaried and informal self-employed sectors. Since the informal self-employed sector is largely non-tradable and unaffected by formal sector rigidities, these same time series properties can also help identify between models of the real exchange rate.

We begin by developing a model that combines Lucas's (1978) idea of workers having differing levels of entrepreneurial ability, with a small economy trade model of the style most recently elaborated by Obstfeld and Rogoff (1996). In spirit we are similar to Aizenman and Frenkel (1988) in introducing heterogeneous ability, in our case varying entrepreneurial ability, to generate non-stationary behavior in relative tradable (formal) and non-tradable (informal self-employed) earnings.

We also introduce capital adjustment costs consistent with the literature on credit as a barrier to entering self-employment (Evans and Jovanovic 1989) and more generally imperfect capital markets. This corresponds to a more realistic view of barriers to entry into informality, and allows for transitory deviations of all variables from their steady state result without positing nominal wage rigidities in the formal sector (see for example Agenor and Aizenman 1999). It also permits us to view the evolution of self-employed incomes as they are reported - a combination of return to capital and labor ability.

Though the model cannot exhaust all possible patterns of comovements of relative sector sizes and incomes, and the real exchange rate, it does plausibly postulate several 
core identifying relationships to motivate the empirical analysis that are robust to an array of parameter variables and to the modeled adjustment process. The spirit of the exercise is to see how far we can go explaining the comovements of the three series without recourse to imposing rigidities.

\subsection{Background}

The traditional "dualistic" view sees the informal sector as the residual of highly distorted LDC labor markets. Unions or government regulation push wages above their equilibrium level, rationing workers into the inferior informal sector where they enjoy no labor protections. However, an emerging literature argues that as a first approximation, this sector should be treated as an unregulated/unprotected entrepreneurial sector that may be desirable to many workers both because of the desire for independence and the misalignment of implicit and explicit labor taxes with perceived benefits. In this case, workers may be choosing to be their own bosses and though becoming unprotected, they reach a higher level of welfare. We argue here that both the "integrated" and "segmented" views should be seen as special cases of the same model: The informal sector may very well be a prosperous non-tradables sector, but one which also contains involuntarily informal workers. The relative shares of voluntary and involuntary worker will reflect the degree of segmentation in the labor market which can vary depending on the shocks to the economy.

Empirically, in the absence of segmentation, we demonstrate that we should expect relative sector size and relative remuneration to move together across time. However, should formal sector rigidities become very binding, perhaps due to a negative shock to formal sector productivity, the overall composition of the sector can be shifted such that it behaves in the more traditional dualistic way: relative earnings move against relative sector size as workers rationed into the informal self-employed sector drive down their relative earnings.

The difference of these two views also has the potential to shed light on the puzzling behavior of real exchange rates following liberalization in many Latin American countries. In the southern cone in the 1970s and in particular Chile, from 1979 to 1982 , Mexico from 1988-1995, Argentina 1990-1995, and Brazil beginning in 1992, the 
exchange rate appreciated, often dramatically following stabilization policies that fixed the nominal exchange rate and liberalized capital markets. ${ }^{1}$ Loosely extending Calvo and Vegh's (1994) typology, two types of explanations have emerged, those relying on backward-looking price and wage behavior (Rodriguez 1982, Dornbusch 1982, Edward and Cox- Edwards 1987, Calvo and Vegh 1994) ${ }^{2}$ and those focusing on "real" phenomena arising from credibility problems (Calvo 1986, Calvo and Vegh 1993) wealth effects do either to falling inflation or expected productivity effects (Helpman and Razin 1987 Schmidt Hebbel 1988, Conley and Maloney 1995) or removing inflationary distortions (De Gregorio, Guidotti, and Vegh 1998, Roldos 1997, Uribe 1997). Central to the Chilean post-mortems of the early 1980s, this dichotomy between "inertial" (Dornbusch and Werner 1995, Edwards 1996) vs "real” (Carstens and Gil-Diaz 1996) explanations remained salient in the discussions of the Mexican peso appreciation of the early 1990s, and Rebelo and Vegh's (1995) efforts to nest and evaluate competing theories of post-stabilization behavior.

The nature of the labor market data we work with here offers the potential to inform these debates. First, the informal self-employed are concentrated in nontradables: Argentina 87\%, Brazil 92\%, Chile 86\%, Colombia 87\%, Mexico 83\%. Second, almost by definition, their incomes are less affected by official regulations. These two characteristics make them ideal for analyzing exchange rate movements in the context of a small economy model, and the relative movement of relative informal/formal wages and sectors sizes and help identify the presence of formal sector rigidities, and inertial forces in exchange rate movements.

As an example, returning to the canonical Chilean case, figure 1, shows that in the 1960s and early 1970s, relative sector sizes and relative incomes moved oppositely, suggesting that under the progressive Christian Democratic government and later under the Socialist government of Salvador Allende, nominal rigidities in formal sector wage

\footnotetext{
1 The exchange rate is defined as the price of non-tradables relative to tradables $\mathrm{P}^{\mathrm{n}} / \mathrm{P}^{\mathrm{t}}$ which can be shown to map into the more standard exchange rate adjusted ratio of price indices EP*/P under most conditions. The real exchange rates for Argentina, Brazil, Colombia and Mexico are displayed in Figure 1 in the Appendix A.

${ }^{2}$ It should be noted that Calvo and Vegh show that backward looking price behavior can explain the stylized facts only if the intra-temporal elasticity of substitution between traded and non traded goods is smaller than the intertemporal rate elasticity of substitution which they find implausible.
} 
setting did, in fact, lead to a segmented labor market. However, during the period of exchange rate appreciation of 1975-1982, the two series move together, suggesting that the currency movements were not driven by backward indexing of formal sector wages. Further, the fact that the formal sector was expanding during this period suggests that a strong productivity shock to the formal sector may have been driving both labor force and exchange rate variables in a Balassa-type effect.

For two other important cases, Mexico and Argentina, the appreciations in 19881993 and 1988-94 respectively occur simultaneously with increases in informal nontradables sector and relative wages suggesting a largely desirable expansion of the informal non-tradables sector and hence a "real" appreciation of the exchange rate. ${ }^{3}$ In these cases, possibly increases in demand for non-tradables may have provided the initial impetus to appreciation. The nascent negative co-movements after 1991 in Mexico offer potential evidence that after the first four years of appreciation, there were formal sector rigidities that were only resolved with the nominal depreciation. At this point, the still negative but now inverted comovements of relative wages and sector sizes suggests the recovery from a period of significant segmentation. The behavior in Argentina seems less clear cut although it suggests a similar story- the appreciation of the ER is accompanied by positive wage/sector size comovement suggesting, again, a boom to the non-tradables sector. The secular increase in informal work in Brazil (figure 1d) after 1987 concomitant with a secular rise in the relative wage in the sector also suggests that this evolution was desirable for many workers and this seems broadly concomitant with the real exchange rate appreciation across the latter half of the period, again consistent with a non-tradable demand led view.

Finally, very sharp negative co-movements in Colombia at the end of the 1990s suggest strong rigidities in the labor market leading to very large rationing out of workers from the formal sector. The sharp real exchange rate beginning in 1995 may reflect this inertial behavior which the nominal depreciation at the end of the period helped offset.

For the countries where the data permit, Brazil and to a lesser extent Mexico and Colombia, the more systematic empirical work of the second half of the paper confirms these initial views.

\footnotetext{
${ }^{3}$ See Maloney (1998)
} 


\section{A Model}

We consider the case of a small economy that produces two composite goods, tradables and non-tradables. The formal sector is assumed to produce tradables $(\mathrm{T})$, the numeraire, while the production of non-tradables is concentrated in the informal sector $(\mathrm{N})$. All workers are homogenous when salaried in the formal sector. However, workers in the informal sector are self-employed and following Lucas, individuals (j) differ in terms of entrepreneurial capability, $\phi_{\mathrm{j}}$ distributed uniformly on [0,1]. For simplicity, we also normalized the labor force to unity so that, provided that the economy is not in a corner solution, the value of entrepreneurial ability of individual $\mathrm{m}$, who is indifferent between salaried work and self-employment, also corresponds to the size of formal labor force. We set $\phi_{m}=\phi^{*}$. Then, $\phi^{*}=L_{T}$. This effectively maintains the usual labor supply constraint, but builds in a decrease in marginal entrepreneurial ability as labor shifts toward self-employment.

Formal output $Y_{T}$ is given by constant-returns production functions of the capital $K_{T}$ and labor $L_{T}$ employed in sector $T$,

$Y_{T}=A_{T} F\left(K_{T}, L_{T}\right)=A_{T} K_{T}^{\alpha_{T}} L_{T}^{1-\alpha_{T}}$

Production of individual $j$ in the self-employment sector is given by

$y_{j}=A_{N} \phi_{j} k_{j}^{\alpha_{N}}$

We assume that capital is mobile both internationally and across sectors but not instantaneously. Capital markets are not perfect for the informal and, as Evans and Jovanovic demonstrated for the US, entrepreneurs are often credit constrained. Those entering self-employment must install some capital the period before producing and pay a deadweight installation cost (paid in terms of tradables) of $\frac{\chi}{2}\left(\frac{I_{j}^{2}}{h\left(k_{j}\right)}\right)$, where $I j$ represents the change in capital stock between two successive periods for self-employed 
individual $j$ and $\chi$ is inversely related to the speed of adjustment. $h\left(k_{j}\right)$ is a linear function of capital accumulated by the individual self-employed $j$. We further assume that individuals willing to leave self-employment must dispose of all the capital they have in place before they become employed in the formal sector. However, due to imperfect capital markets, they face symmetrical adjustment costs. This specification ensures that (de)installation costs are always finite. Further, since marginal costs of capital installation are increasing, capital adjustment will not happen instantaneously. Labor is allocated only mobile between the two sectors and as will be shown, since the entrepreneur must install capital before moving, labor also does not adjust fully within one period and differentials in net remuneration among sectors are not instantly arbitraged by labor flows. This permits us to analyze both steady state movements in relative wages, relative sector sizes and exchange rates, but, also transitional dynamics. ${ }^{4}$ As to labor, it can migrate only between sectors within the economy.

\subsection{The firm}

The representative formal sector firm maximizes

$\max \sum_{s=t}^{\infty}\left(\frac{1}{1+r}\right)^{s-t}\left[A_{T, s} F\left(K_{T, s}, L_{T, s}\right)-w_{T, s} L_{T, s}-I_{T, s}\right]$

where $w T, s$ is the wage (gross) prevailing in the tradables sector at time $\mathrm{t}=\mathrm{s}$. The world interest rate $r$, expressed in terms of tradables, is assumed to be constant.

Let us define the capitallabor ratios in traded goods production as $k_{T}=K_{T} / L_{T}$, and rewrite outputs per employed worker as $y_{T}=A_{T} f\left(k_{T}\right)$. The first order conditions are given by:

$$
\begin{aligned}
& A_{T} f^{\prime}\left(k_{T}\right)=r \\
& A_{T}\left[f\left(k_{T}\right)-f^{\prime}\left(k_{T}\right) k_{T}\right]=w_{T}
\end{aligned}
$$

\footnotetext{
${ }^{4}$ As usually assumed, one unit of tradables can be transformed into a unit of capital at no cost. The reverse is also true. Non tradables can be used only for consumption. Capital can be used for production and then consumed (as a tradable) at the end of the same period.
} 
Because $r$ is the world interest rate expressed in terms of tradables, it must correspond to the marginal product of capital in the formal sector as indicated by equation (1). Equation (2) simply states that the wage prevailing in the sector equals labor marginal productivity. Because both factors do not shift instantaneously across sectors, equations (1) and (2) may fail to hold ex-post in the event of unanticipated shocks.

In the informal sector, individual $j$ maximizes

$\sum_{s=t}^{\infty}\left(\frac{1}{1+r}\right)^{s-t}\left[p_{s} A_{N, s} \phi_{j} k_{j, s}^{\alpha_{N}}-\frac{\chi}{2}\left(\frac{I_{j, s}^{2}}{h\left(k_{j, s}\right)}\right)-I_{j, s}\right] \quad$ subject to: $I_{j, s}=k_{j, s+1}-k_{j, s}$.

The first order condition is given by

$I_{j, s}=\frac{q_{s}-1}{\chi} h\left(k_{j, s}\right)$

$q_{s+1}-q_{s}=r q_{s}-p_{s+1} A_{N, s+1} g^{\prime}\left(k_{j, s+1}\right)-\frac{1}{2 \chi}\left(q_{s+1}-1\right)^{2}$

where $q$ denotes the shadow price of installed capital in non-tradables and $p$ denotes the price of non-tradables relative to the price of tradables. In other words, $p$ is simply the inverse of the real exchange rate defined as the relative price of traded goods in terms of non-traded goods. Equation (3) indicates that investment is positive only for values of $q$ larger than 1. Equation (4) is a standard investment Euler equation. It must also be true in the long run for all self-employed individuals that returns to capital equal the market rate of interest

$p A_{N} \phi_{j} \alpha_{N} k_{j}^{\alpha_{N}-1}=r$

and that the pivotal individual is indifferent between wage work and self-employment, we have

$\left(1-\alpha_{N}\right) p A_{N} \phi * k_{*}^{\alpha_{N}}=w_{T}$ 


\subsection{The Consumer}

As is standard, we assume that the economy is inhabited by an infinitely-lived representative consumer whose demands and asset holdings are identified with aggregate national counterparts and who maximizes a lifetime utility function of the form

$U_{t}=\sum_{s=t}^{\infty} \beta^{s-t} u\left(\Phi\left(C_{T}, C_{N}\right)\right)$.

Where $C_{T}$ and $C_{N}$ stand for consumption in the tradables and non-tradables sectors, respectively, $\Phi\left(C_{T}, C_{N}\right)$ is a linear homogenous function of its arguments and $u($.$) is$ isoelastic with intertemporal substitution elasticity $\sigma$. The representative consumer faces a lifetime budget constraint

$$
\sum_{s=t}^{\infty}\left(\frac{1}{1+r}\right)^{s-t}\left(C_{T, s}+p C_{N, s}\right)=(1+r) Q_{t}+\sum_{s=t}^{\infty}\left(\frac{1}{1+r}\right)^{s-t}\left(w_{T, s} L_{T, s}+\left(1-\alpha_{N}\right) \int_{\phi^{*}}^{1} p_{s} A_{N, s} \phi_{j} k_{j, s}^{\alpha_{N}} d \phi_{j}-\frac{\chi}{2}\left(\frac{I_{N, s}^{2}}{h\left(K_{N, s}\right)}\right)\right.
$$

where national financial wealth $Q_{t}=B_{t}+K_{N, t}+K_{T, t}$ is measured in terms of tradables and $B$ stands for net aggregate holdings of foreign assets. $\phi^{*}$ is the ability of the individual who is indifferent between self-employment and wage work. We will be more precise about the latter definition below. $\mathrm{I}_{\mathrm{N}}, \mathrm{s}$ represents total investment and $\mathrm{K}_{\mathrm{N}}, \mathrm{s}$ total capital accumulated in the informal sector at date s.

For the general case of a CES utility function ${ }^{5}$

$\frac{C_{T}}{C_{N}}=\frac{\gamma}{(1-\gamma)} p^{\theta}$

relative intratemporal consumption depends only on the relative price $p$ and not upon consumer's spending level where $\gamma$ indicates the weight of the tradable good in the utility function. Moreover,

\footnotetext{
${ }^{5}$ See Obsfeld and Rogoff (1996, pp 226-235) for a full derivation.
} 


$$
\frac{C_{T, s+1}}{C_{N, s+1}}=\left(\frac{p_{s+1}}{p_{s}}\right)^{\theta} \frac{C_{T, s}}{C_{N, s}}
$$

A rise in non-tradables relative price induces a rise in tradables consumption growth relative to non-tradables consumption growth. Note that if $\sigma=\theta$, tradables consumption remains constant along the perfect foresight paths.

Since, by assumption non-tradables can only be consumed, in equilibrium consumption equals production in the informal sector. Substitution and combination of the Euler equation for tradables consumption with the lifetime budget constraint of the representative consumer yields an expression for the optimal consumption of tradables

$$
C_{T, t}=\frac{(1+r) B_{t}+\sum_{s=t}^{\infty}\left(\frac{1}{1+r}\right)^{s-t}\left(Y_{T, s}-I_{s}-\frac{\chi}{2}\left(\frac{I_{N, s}^{2}}{h\left(K_{N, s}\right)}\right)\right)}{\sum_{s=t}^{\infty}\left(\frac{1}{1+r}\right)^{s-t}\left(\frac{P_{t}}{P_{s}}\right)^{\sigma-\theta}},
$$

where $\mathrm{P}$ is the price index $\left.\mathrm{P}=\left[\gamma+(1-\gamma) p^{1-\theta}\right]^{1 / 1-\theta}\right]$ which is increasing in $\mathrm{p}$.

\subsection{Responses to Productivity and Demand Shocks}

Before turning to the dynamics of the economy, we first describe its steady state equilibrium and assess the impact of permanent productivity and consumption shocks. We then introduce a wage rigidity in the formal sector. The results of all exercises are tabulated in Table 1.

\subsubsection{Shocks in the Long Run}

Productivity shocks are represented by a permanent variation in the $A$ productivity scale coefficients and demand shocks by a permanent variation in the $\gamma$ parameter. In the 
following, variables with hats refer to rates of change $\left(\hat{x}=\frac{\Delta x}{x}\right)$. Log differentiation leads to the following results, assuming that initially $p=1$ and initial $\gamma$ is equal to one half.

The real exchange rate: Differentiating (4') and aggregating across all $\mathrm{j}$ gives $\hat{p}+\hat{A}_{N}+\hat{\phi}^{*}-\left(1-\alpha_{N}\right) \hat{k}_{*}=\hat{r}=0$

Although individual ability remains constant by assumption, $\hat{\phi}_{j}=0$ and hence the capital growth rate is the same for everyone, the labor reallocation after a shock results in a change in the pivotal individual so that $\hat{\phi} *$ is no longer equal to zero for the labor force as a whole. By the same logic

$\hat{p}+\hat{A}_{N}+\hat{\phi} *+\alpha_{N} \hat{k}_{*}=\hat{w}_{T}$

where $\hat{k}_{*}=\hat{k}_{j}$ and is given by equation (4'). Defining $\eta_{L, T}=\frac{w_{T} L_{T}}{Y_{T}}$, labors' share in tradables output, $\hat{w}_{T}=\frac{1}{\eta_{L T}} \hat{A}_{T}$, and then $\hat{p}=\frac{1-\alpha_{N}}{\eta_{L T}} \hat{A}_{T}-\hat{A}_{N}$

This simply restates the Balassa-Samuelson result that, for values of $\frac{1-\alpha_{N}}{\eta_{L T}}$ close to 1 , the real exchange rate is determined by the relative rates of productivity growth.

Relative Sector Size: Demand for tradables and non-tradables can be re-written as, respectively

$$
C_{T}=\frac{\gamma Z}{\gamma+(1-\gamma) p^{1-\theta}}
$$

and

$$
C_{N}=\frac{p^{-\theta}(1-\gamma) Z}{\gamma+(1-\gamma) p^{1-\theta}}
$$

where $\quad Z=w_{T} L_{T}+\left(1-\alpha_{N}\right) \int_{\phi^{*}}^{1}\left(p A_{N} \phi_{j} k_{j}^{\alpha_{N}}\right) d \phi_{j}+r \tilde{Q}$

In order to simplify the analysis we assume that total financial wealth remains constant across steady state. We implicitly assume that any variation in the total level of physical 
capital is fully offset by an equal variation of opposite sign in foreign assets holdings. This allows us to write

$$
\hat{Z}=\varphi_{L T}\left[\hat{w}_{T}+\hat{L}_{T}\right]+\varphi_{s e}\left[\frac{1}{1-\alpha_{N}} \hat{A}_{N}+\frac{1}{1-\alpha_{N}} \hat{p}-\hat{\phi} * \Psi\right]
$$

where $\varphi_{L T}=\frac{w_{T} L_{T}}{Z}, \varphi_{s e}=\frac{\left(1-\alpha_{N}\right) \int_{\phi^{*}}^{1}\left(p A_{N} \phi_{j} k_{j}^{\alpha_{N}}\right) d \phi_{j}}{Z}$ and $\Psi=\frac{2-\alpha_{N}}{1-\alpha_{N}}\left[\frac{\left(\phi^{*}\right)^{\frac{2-\alpha_{N}}{1-\alpha_{N}}}}{1-\left(\phi^{*}\right)^{\frac{2-\alpha_{N}}{1-\alpha_{N}}}}\right]$.

Changes in non tradables consumption can be written as

$$
\hat{C}_{N}=-\hat{\gamma}+\hat{Z}-(\theta \gamma+(1-\gamma)) \hat{p}
$$

and changes in total production in the informal sector by

$$
\hat{Y}_{N}=\frac{1}{1-\alpha_{N}}\left[\hat{A}_{N}+\hat{p}\right]-B \hat{\phi} *
$$

Since non tradable goods market equilibrium requires that $\hat{C}_{N}=\hat{Y}_{N}$, the entrepreneurial ability of the pivotal worker, and implicitly, the share of the workforce in tradables, can be written as

$$
\hat{\phi}^{*}=-\Omega_{1}\left[-\hat{\gamma}+\frac{\hat{A}_{T}}{\eta_{L T}}\left[\varphi_{L T}+\varphi_{s e}-1+\left(1-\alpha_{N}\right)(\gamma(1-\theta)-1)\right]+\hat{A}_{N}(1-\gamma(1-\theta))\right],
$$

where $\Omega_{1}=\left[\left(1-\varphi_{s e}\right) \Psi+\varphi_{L T}\right]^{-1}$

Relative Earnings: The change in informal production expressed in tradables units is now

$$
\hat{p Y_{N}}=\frac{\hat{A}_{T}}{\eta_{L T}}-\Psi \hat{\phi^{*}}=\frac{\hat{A}_{T}}{\eta_{L T}}+\Omega_{2}\left[-\hat{\gamma}+\frac{\hat{A}_{T}}{\eta_{L T}}\left[\varphi_{L T}+\varphi_{s e}-1+\left(1-\alpha_{N}\right)(\gamma(1-\theta)-1)\right]+\hat{A}_{N}(1-\gamma(1-\theta))\right]
$$

where $\Omega_{2}=\frac{\Psi}{\left(1-\varphi_{s e}\right) \Psi+\varphi_{L T}}$. The relative change in total production also corresponds to the relative variation in entrepreneurs earnings (denoted by $w_{N j}$ thereafter) as the latter is a constant proportion of the former. 
The change in average informal production (entrepreneurs earnings) expressed in terms of tradables units can be written as:

$$
\begin{aligned}
& E\left(p \hat{Y}_{N}\right)=\frac{\hat{A}_{T}}{\eta_{L T}}-\Psi \hat{\phi} *+\frac{\phi^{*}}{1-\phi^{*}} \hat{\phi}^{*} \\
& =\frac{\hat{A}_{T}}{\eta_{L T}}+\Omega_{3}\left[-\hat{\gamma}+\frac{\hat{A}_{T}}{\eta_{L T}}\left[\varphi_{L T}+\varphi_{s e}-1+\left(1-\alpha_{N}\right)(\gamma(1-\theta)-1)\right]+\hat{A}_{N}(1-\gamma(1-\theta))\right]
\end{aligned}
$$

where

$\Omega_{3}=\frac{\Psi-\frac{\phi^{*}}{1-\phi^{*}}}{\left(1-\varphi_{s e}\right) \Psi+\varphi_{L T}}>0$. It is straightforward to verify that $\Omega_{3}<\Omega_{2}$.

\section{Productivity Shock to the Formal/Tradables Sector}

In the case where $\hat{A}_{T}>0, \hat{A}_{N}=0$ and $\hat{\gamma}=0$, consistent with BalassaSamuelson, the real exchange rate appreciates - non-tradables become more expensive relative to tradables. Both sectors become relatively more capital intensive and as a consequence net earnings are higher. The direction of change of the employment share of self-employment depends on the sign of $\left[\varphi_{L T}+\varphi_{s e}-1+\left(1-\alpha_{N}\right)(\gamma(1-\theta)-1)\right]$. It is unambiguously negative when $\theta \geq 1$ and labor flows toward the formal sector and $\hat{\phi}^{*}>0$. However, for smaller values of $\theta$, the wealth effect may prevail over the substitution effect and both consumption of non-tradables and employment in the informal sector may increase in levels. A sufficient condition for observing $\hat{\phi}^{*}>0$ for any $\theta>0$ is given by

$$
\left(1-\varphi_{s e}-\varphi_{L T}\right)>\left(1-\alpha_{N}\right)(\gamma-1)
$$

As by definition $\gamma$ is smaller than 1 then, condition (8) is always satisfied. Total informal production, measured in tradables units, depends on the sign of 
$\frac{\hat{A}_{T}}{\eta_{L T}}\left[1-\Omega_{2}\left[1-\varphi_{L T}-\varphi_{s e}-\left(1-\alpha_{N}\right)(\gamma(1-\theta)-1)\right]\right]$

In the case of Cobb-Douglas preferences, it is straightforward to see that $0<1-\Omega_{2}\left[1-\varphi_{L T}-\varphi_{s e}+\left(1-\alpha_{N}\right) \gamma\right]<1$ for values of $\Omega_{2}$ close enough to unity, and the total value of informal production increases. Since $\Omega_{3}<\Omega_{2}$, this is also true for average production and thus average entrepreneurs earnings. The reason is twofold. First the price of non-tradables increases and second, only the most able entrepreneurs remain in the informal sector. For larger values of $\Omega_{2}$ and $\Omega_{3}$ and or $\gamma$ then the expression into brackets is likely to become negative. Since $\hat{w}_{T}=\frac{\hat{A}_{T}}{\eta_{L T}}$, on average self-employed earnings fall relative to workers earnings in the formal sector for any value of $\Omega_{2}, \Omega_{3}$ and $\theta$.

In sum, for any positive value of $\theta$, we expect to observe relative earnings and relative sector sizes to positively co-move. In addition they move with the real exchange rate.

\section{Productivity Shock to the Informal/Non-Tradables Sector}

In the case where $\hat{A}_{T}=0, \hat{A}_{N}>0$, and $\hat{\gamma}=0$ the real exchange rate decreases in proportion to the productivity shock in non tradables and neither capital intensity nor self-employed earnings are affected. The impact on informal employment is determined by the sign of $(1-\gamma(1-\theta))$, which is positive for any positive value of the intra-temporal elasticity of substitution. In all situations average earnings and participation rate in the informal sector increase relative to their counterpart in the tradables sector and move together although they move against the real exchange rate.

However, it is hard to identify a case with a negative non-tradables productivity shock against the mainstream case of a strong positive shock to tradables, for instance, in the case of Chile 1979-82 although the boom in real estate and construction across that period (see Conley and Maloney 1995) weighs in favor of the latter. 


\section{Shift in Preferences toward Non-Tradables}

A shift in preferences, for example, towards non-tradables consumption $\hat{A}_{T}=0$, $\hat{A}_{N}=0$ and $\hat{\gamma}<0$ increases self-employment as well as absolute and relative consumption of non-tradables. Absolute and relative average earnings of the selfemployed increase while wages in the formal sector remain at their initial level. Again, we observe co-movements in relative sector sizes and returns. In the long run, there is no change in the real exchange rate although, as we discuss below, this is not true in the short run.

\section{Negative Formal/Tradables Productivity Shock with Formal Sector Wage Rigidities}

Unions or mandatory minimum wages may introduce downward wage rigidities in the formal sector that can reverse many of the findings above. A negative shock to productivity in the tradables sector translates into wage downward pressures in the formal sector. However, as this cannot occur, labor must migrate to the informal sector. Because capital returns are tied to the world interest rate, the outflow of labor in the formal sector is more pronounced than in the flexible case. This outflow corresponds to $\hat{L}_{T}=\frac{\hat{A}_{T}}{\alpha_{T}}(=\hat{\phi} *)<0$.

Equilibrium of the demand and supply conditions in the non-tradables sector

$$
\hat{C}_{N}=\left(\varphi_{L T}-\varphi_{s e} \Psi\right) \frac{\hat{A}_{T}}{\alpha_{T}}+\left[\varphi_{s e} \frac{\alpha_{N}}{1-\alpha_{N}}-(\theta \gamma+(1-\gamma))\right] \hat{p}
$$

and

$$
\hat{Y}_{N}=\frac{\alpha_{N}}{1-\alpha_{N}} \hat{p}-\Psi \frac{\hat{A}_{T}}{\alpha_{T}}
$$

gives

$$
\hat{p}=\frac{\hat{A}_{T}}{\alpha_{T}}\left[\frac{\left(1-\alpha_{N}\right)\left(\varphi_{L T}+\left(1-\varphi_{s e}\right) \Psi\right)}{\alpha_{N}\left(1-\varphi_{s e}\right)+\left(1-\alpha_{N}\right)(\gamma \theta+(1-\gamma))}\right]
$$


which is negative for any $\theta>0$ as is

$$
E\left(p \hat{Y}_{N}\right)=\frac{\hat{A}_{T}}{\alpha_{T}}\left[\frac{\varphi_{L T}+\left(1-\varphi_{s e}\right) \Psi}{\alpha_{N}\left(1-\varphi_{s e}\right)+\left(1-\alpha_{N}\right)(\gamma \theta+(1-\gamma))}-\left[\Psi-\frac{\phi^{*}}{1-\phi^{*}}\right]\right]
$$

As labor migrates towards the informal sector, production rises, the real exchange rate depreciates, and average earnings in the informal sector fall. Moreover, as workers cannot migrate back to the formal sector, those whose entrepreneurial ability is relatively low earn less than what they would get in the formal sector. For those workers "trapped" in the informal sector earnings performance has worsened relative to those employed in the formal sector as earnings in the formal sector are preserved by institutional rigidities. With the exception of the implausible case where $\theta<\left(\varphi_{s e}-\gamma\right) / \gamma$, the two labor force series move against each other. Critically, the same result would hold in the case where indexation of wages to past inflation forces formal sector wages above equilibrium: we should see relative sector sizes and incomes move against each other.

\subsubsection{Short Run Equilibrium and Dynamics}

The adjustment to the steady state may depend on the relative values of $\sigma$ and $\theta$ although the previous section showed that long run properties of the economy are exclusively dictated by the absolute value of $\theta$. To simplify, we start with the case where $\theta=\sigma=1$ and then refer to alternative parameterizations. To refresh, $\sigma>\theta$ implies that tradables consumption reacts more to variations in the gross real interest rate 6 induced by a variation in the relative price of non-tradables than to the variation in the relative price itself.

Linearizing equations (3) and (4) around the steady state $\bar{q}=1, \bar{k}_{j}$ we obtain

$$
k_{j, t+1}-k_{j, t}=\frac{q_{t}-1}{\chi} h\left(\bar{k}_{j}\right)
$$

\footnotetext{
${ }^{6}$ The gross real interest rate denoted by $r^{c}$ verifies $1+r_{t+1}^{c}=\frac{(1+r) P_{t}}{P_{t+1}}$.
} 
$q_{s+1}-q_{s}=r\left[\left(1-\alpha_{N}\right) \frac{h\left(\bar{k}_{j}\right)}{\chi} \bar{k}_{j}+1\right]\left(q_{t}-1\right)+r\left[\left(1-\alpha_{N}\right) \bar{k}_{j}\right]\left(k_{j, t}-\bar{k}_{j}\right)$

The equations $\Delta k_{j}=0$ and $\Delta q_{j}=0$ are depicted in a two-equation phase diagram in $q$ and $k_{j}$ that shows the dynamics of self-employed individuals investment decisions (figure 2). The perfect foresight path is indicated by the line denoted by SS.

As the steady level of investment chosen by each individual is not identical, we expect to observe that a common shock affects differently heterogeneous individuals differently. Should a shock lead to contraction of the self-employment sector, those whose entrepreneurial ability falls below the threshold steady state value of $\phi^{*}$ (those who would be better off in the wage work sector), the perfect foresight path leads to zero capital and a zero capital shadow value at steady state as depicted in figure 3 . Should self-employment expand, new-entrants invest initially $I_{0}=\frac{1-r}{r \chi} a$ independently of the wage prevailing in the formal sector since the initial shadow value of their capital is above one $\left(q_{0}=1 / r\right)$.

Inter-sectoral worker movements are not expected to be simultaneous because of entrepreneurial ability heterogeneity across individuals. More able individuals are the first to enter self-employment and the last to leave it. A sketch proof of these results is presented in appendix A.

\section{Productivity Shock to the Formal/Tradables Sector}

Production of tradables increases and so do labor and capital returns, leading to increased demand for both types of goods and causing $p$ to rise to clear the non-tradables market. Along the perfect foresight transition path, some self-employed find it more profitable to move to the formal sector. As a consequence the shadow value of the capital they use at the end of the period following the shock falls short below 1 and tends to zero in the long run, and they decumulate capital. Those whose sequence of returns from selfemployment remains above that of the formal wage face $q>1$ and they accumulate more capital. 
On impact, no adjustment can take place because formal firms must wait for the following period to adjust their capital and self-employed can migrate only once the capital they have in place at the moment of the shock has been completely dismantled, that is not before the following period. Then, prices are the only adjustment element. On impact, $E\left(p \hat{Y}_{N}\right)=\frac{\varphi_{L T}\left(1-\alpha_{N}\right)}{\left(1-\alpha_{N}\right)(\theta \gamma+(1-\gamma))-\varphi_{s e} \alpha_{N}} \hat{A}_{T}$, which corresponds to the initial rise in $p$. It can be shown that average self-employed earnings at steady state are lower than the level they reach on impact while the opposite is true for the formal wage. Then along the perfect foresight transition path, average earnings in the informal sector are expected to fall relative to wage changes in the formal sector. As condition (8) is always satisfied, the informal share is also expected to fall, as indicated in the previous section. Moreover, along the adjustment path, both sectors become more capital intensive, production in tradables increases unambiguously and the real exchange rate appreciates. Then, towards the long run $w_{T} / w_{N}$ increases, $L_{T} / L_{N}$ falls and $p$ rises relative to its initial level. Price overshooting and opposite movements of earnings and participation in the informal sector could never be observed. The relative ranking of $\sigma$ and $\theta$ may affect the length of adjustment but preserve dynamics and long run properties. Indeed, $C_{T, t}$ is given by (7) which suggests that the level of tradables consumption along the saddle path is affected by variations in $p$ in a manner that could either reinforce or offset the impact of a shock.

The impact of a rise in $p$ on consumption bundles is dampened by consumers' inter-temporal considerations in the case where $\sigma>\theta$ and amplified in the opposite case. In the former case, consumption of non-tradables falls less rapidly relative to consumption in the tradables than in the case where $\sigma<\theta$. This implies that migration occurs over a longer period of time when inter-temporal substitution considerations prevail over intra-temporal substitution considerations.

\section{Productivity Shock to the Informal/Non-Tradables Sector}

Again dynamics are driven by the importance of inter-temporal relative to that of intra-temporal considerations. On impact the real exchange rate is expected to fall to offset the positive productivity shock in order to keep the non-tradables market in equilibrium. However, the expected fall in $p$ leads to a rise in demand for non-tradables. 
This rise in demand increases as $\theta$ takes higher values relative to $\sigma$. That is, for $\sigma<\theta$ we observe some undershooting of $p$ along the transition path. Undershooting describes the fact that $p$ falls to the level that offsets the impact of the productivity shock only when the economy reaches its new steady state. Whenever, $\sigma>\theta$ consumption of tradables increases as $p$ falls. The positive impact on the demand for non-tradables is smaller than in the previous case. This implies that the real exchange rate undershooting is less pronounced during the transition to the steady state than in the previous case. In other words, when $\sigma<\theta$ adjustment is expected to take place over a shorter period than in any other situation.

From previous section findings we have that at steady state, neither capital intensity nor self-employed earnings are affected on an individual basis. This implies that selfemployed individuals already in place at the occurrence of the shock, do not modify their capital stock as indicated by equations (3') and (4'). Nevertheless, they increase their production as the initial real effect of the technological shock is positive. They return progressively to their pre-shock level of production as migration takes place.

\section{Shift in Preferences toward Non-Tradables}

On impact, the real exchange rate appreciates, relative informal earnings rise, and the shadow value of capital increases. This attracts new entrepreneurs to the sector, expanding non-tradables supply and the relative price of non-tradables begins to return to its initial, relative productivity determined level. Again the adjustment is more rapid when $\sigma>\theta$ and slowed in the opposite case. This represents an important case where both $w_{T} / w_{N}$ and $L_{T} / L_{N}$ fall concomitant with an exchange rate depreciation, and then an appreciation.

\section{Negative Formal/Tradables Productivity Shock with Formal Sector Wage Rigidities}

Because of downward wages rigidity, consumption levels are not affected on impact and $p$ is not affected. However, released labor from the formal sector now flows to the non-tradable sector increasing its production, driving down $p$, and reducing average self-employed earnings. At the end of the first period, the tradables labor market is reequilibrated and outflow of capital again equalizes the marginal productivity of capital to 
the world interest rate. For those self-employed already in place, the fall in $p$ observed along the transition path, leads to capital decumulation. This effect is stronger in the case where $\sigma>\theta$ and $\theta>\frac{\varphi_{s e}-\gamma}{\gamma}$. In the symmetric case, we would still observe capital withdrawal from the informal sector but of a smaller size. Indeed, the non-tradables' relative price can rise on impact ${ }^{7}$, which slows down the path of capital decumulation in that sector. As a consequence, average earnings in the self-employment sector increase in the long run.

Nevertheless this result should be regarded as a particular case. In the general case, those workers "forced" to become self-employed, even when on their optimal production path, are stuck in a position with earnings below the formal wage. Along the transition towards steady state, average earnings in the informal sector have fallen relative to the formal salary while the size of self-employment has increased.

\section{Methodology and Empirical Results:}

The analysis above makes two important points. First, using very standard models, it is clear that theory implies relationships between our labor market variables and the real exchange rate. Second, independent of skill heterogene ity and adjustment costs, under no conditions can we generate a counter movement of relative sector sizes and earnings in the absence of a wage rigidity. This implies that any appreciation attributed to inertia or rigidities in the formal sector must be associated with opposing movements in sector size and earnings. Third, even in the absence of wage rigidities, the correlations between the real exchange rate and labor market variables will depend on the relative magnitudes of intra and intertemporal elasticities.

In this section, we use the multivariate Johansen approach (1988) to explore possible cointegration relationship in these three variables with the aim of establishing the degree of dualism in the labor market and driving force behind exchange rate

\footnotetext{
${ }^{7}$ This is verified if $\alpha_{N}>\frac{1-\gamma}{1-\gamma-\varphi_{s e}}$
} 
movements Mexico, Brazil and Colombia. ${ }^{8,9}$ Although cointegration is sometimes given the economic interpretation of capturing "long run" relations, fundamentally it is a statistical relationship existing among non-stationary series. In our case, both relative sector sizes and the real exchange rate can plausibly be posited as I(1) and they always appear to be so in the analysis. Changing aggregate skill levels postulated in section 2 suggest no reason to assume the wages ex ante to be $\mathrm{I}(0)$ and even if they were, a slow adjustment process could lead to apparent non-stationary behavior within the sample analyzed. $^{10}$

We then use recursive cointegration estimation techniques to explore the stability of the cointegration space over time and we apply LR-test to test hypotheses on the coefficients of the cointegration vectors in order to provide empirical evidence to test the various predictions of the model and to extract some conclusions about labor market rigidities and the source of appreciations in the three countries.

\subsection{Data}

We use quarterly data for Mexico, Brazil and Colombia on the log-transformed real exchange rate, $p$, the wage ratio of formal over self-employed workers, $W_{T} / W_{N}$, and the ratio of the absolute size of formal over the self-employed sector, $n_{T} / n_{N}$. Real exchange rates where taken from IFS, all labor market data were derived from national labor force surveys (Pesquisa Mensual do Emprego for Brazil, Encuesta Nacional de Empleo Urbano for Mexico and Encuesta Nacional de Hogares , Colombia). The work force was defined as only the active male population. Because we are interested in informal workers and not educated workers opening consulting firms, all workers with more than 12 years of education were dropped from the sample.

We use as a definition of informal self-employment either that size is under 6 total workers, or that the worker is not registered with social security. We might also,

\footnotetext{
${ }^{8}$ The statistical concept of a long-run equilibrium underlying cointegration analysis refers to the existence of a stationary relationship among two or more non-stationary time series.

${ }^{9}$ Appendix B contains a brief overview of the multivariate cointegration approach of Johansen (1988).

10 Theoretically, however, it is legitimate to include an $\mathrm{I}(0)$ variable in the cointegrating relationship, although we would expect at least one cointegrating vector to emerge that captures simply the stationary series. In practice, these series were never stationary across our sample and the problem was moot.
} 
following Loayza (1995) focus on evasion of taxes or other regulations although in practice these different dimensions of "informality" are highly correlated and would probably change the analysis little. ${ }^{11}$

In viewing the data, it is worth mentioning that even if remuneration between the two sectors were equilibrated, these would include all monetary and non-monetary remuneration (independence, benefits foregone, taxes avoided, implicit returns to capital, etc.). Thus, even though in most of the countries the informal self-employed appear on average to earn higher incomes this does not account for unobservable types of remuneration. $^{12}$

\subsection{Empirical Analysis}

We estimate separate VAR models for Mexico, Brazil and Colombia. The VAR models include a constant in the cointegration space, different lags for $p, W_{T} / W_{N}$ and $n_{T} / n_{N}$ as well as country specific dummies and these specifications prove sufficient to produce random errors. ${ }^{13}$ The $\lambda_{\text {trace }}$ tests indicate one significant cointegrating vector in all three models (Table 2). Normalizing the cointegration vectors on the $1^{\text {st }}$ element, yields the following estimates for the $\beta$ s (Table 3 ) and $\alpha \mathrm{s}$ (Table 4$)^{14}$ :

The adjustment coefficient of $\Delta n_{T} / n_{N}$ is strongly insignificant for Mexico and borderline significant in the case of Brazil and Colombia. This indicates weak exogeneity of $n_{T} / n_{N}$ and thus provides evidence that $n_{T} / n_{N}$ is driving the system, while $W_{T} / W_{N}$ and $p$ are adjusting to disturbances in the long-run equilibrium.

\footnotetext{
11 Levenson and Maloney (1998) argue that formality, conceived as participation in social institutions (social security, judicial, taxes payment, etc) itself may be largely incidental- social participation in general can be seen as a normal good in the production function that is more desired as firms grow. With growth firms may embrace

${ }^{12}$ See Maloney (1999) for more detail.

13 The model specifications for the three models are presented in Tables 8 and 9 in the Appendix along with tests for long-run exclusion, stationarity and weak-exogeneity (Table 7). All variables appear to be nonstationary and the diagnostics on the residuals of the system show the absence of autocorrelation and indicate normality. A sensitivity analysis for different lag lengths and with and without dummies further indicated robustness of the findings.

${ }^{14}$ Figures 14 to 16 display the recursive trace statistics and indicate stability of the unrestricted cointegration space.
} 


\subsubsection{Identifying the Cointegration Space}

Identifying the cointegration space in the present case translates to sequentially impose restrictions on the cointegration vectors guided by the theoretical considerations of the previous sections. We begin by putting no restrictions on the exchange rate, but focus purely on the evolution of the two labor market variables. Effectively, referring to Table 1, we are testing between the first division between markets with or without wage rigidities. A test that a rise in relative formal employment is accompanied by a rise in relative formal wages (integrated sector size/wage movement), is implemented by restricting the coefficient of the relative formal wage to -1 . A hypothesis test that a relative rise in formal employment is accompanied by a decline in relative formal wages (segmented sector size/wage movement), is implemented by restricting the coefficient of $W_{T} / W_{N}$ to 1 .

Table 5 presents the results for the whole sample. For Mexico, the test of integrated markets can be strongly rejected while the test for segmentation cannot be rejected. For Brazil, the hypothesis of integration cannot be rejected and the hypothesis of segmentation is rejected at the $1 \%$ level. In Colombia, the hypothesis of segmentation can borderline not be rejected but a hypothesis of integration across the whole period can be.

However, recursive cointegration tests of the stability of the cointegration space suggest in all cases the possibility of different relationships for subperiods, consistent with the idea that nominal rigidities may bind in some periods and not in others. Operationally, the trace statistics are calculated initially over a base period and then recalculated for every new observation added until the end of the sample is reached.

Mexico: Figures 4 and 6 show, for Mexico, the test of the hypothesis that the full sample estimate of $\beta$, with the over-identifying restrictions $(1,1, *, *)^{15}$ imposed, is in the space spanned by $\beta_{i}$ in each sub-sample. The test-statistics have been scaled by the $95 \%$ quintile in the $\chi^{2}$ distribution such that unity corresponds to the $5 \%$ significance level. Since the plot of the test statistics is above unity prior to roughly 1995, the hypothesis of segmentation is only accepted from 1995 onwards. A recursive test of the hypothesis of integration (expressed in vector form as $(1,-1, *, *))$ is plotted in Figures 5

\footnotetext{
${ }^{15} \mathrm{~A} *$ indicates that a variable has been left unrestricted.
} 
and 7 and, as Figure 1 suggested, cannot be rejected prior to 1995. These tests confirm that in the recovery period leading up to 1995 , the rise in the informal sector was largely due to greater attractions of the sector itself, and not to labor market rigidities.

Brazil: For Brazil, the data cannot reject integration across the entire period although there are some sub-periods where it is difficult to reject segmentation as suggested by Figure 9.

Colombia: The recursive stability test for Colombia strongly supports the hypothesis of a segmented labor market post 1995 onwards and never supports the view of integration for any subsample. This supports the view that the Colombian labor market does have some formal sector rigidities which were intensified in the post 1995 period. In particular, the rise of the real minimum wage across the period, concomitant with a collapse in formal sector activity due, among other factors, a financial crisis would correspond very well to the story that emerges.

\subsubsection{Further Restrictions on the Cointegration Space}

In the previous section we have left the real exchange rate unrestricted. As our theoretical model shows that a real exchange rate appreciation (depreciation) can be accompanied by an increase (decrease) in the relative informal sector size as well as an increase (decrease) in relative informal wages, further empirical support for our model would be to identify a vector of $(1,-1,-1, *)$ in the cointegration space. We limit our analysis to the cases of Mexico and Brazil since we cannot reject segmentation in the labor market.

For Mexico, we limit our estimation period in this section from the post 1987 recession to the pre Peso crises (1988:01 to 1994:03). We cannot reject the hypothesis test of $(1,-1,-1, *)$ at a conventional level of significance, that is, the real exchange rate appreciation in Mexico prior to the Peso crisis was accompanied by an increase in the relative informal sector size and an increase in relative wages. (Table 6). This is consistent with a positive demand shock to non-tradables, perhaps the boom in construction during the period, driving the exchange rate in the short to medium term, and is inconsistent with the inertial view. Although the cointegration relationship only falls apart after 1995, the cumulative nature of the statistics may hide an earlier 
disequilibrium and the relationship does become less stable as we approach the crisis, consistent with the graphical evidence of segmentation appearing in 1992. In this sense, Carstens and Gil-Diaz were correct that the appreciation was caused by real factors, but Dornbusch and Werner were correct that a nominal depreciation was in order in 1994.

For Brazil we could not reject positive comovement of the relative sector size and the relative wages over the whole sample (see Table 5), though this relationship appears to be stable only from around 1990 onwards (see Figure 8). A test of a coefficient vector of $(1,-1,-1, *)$ being part in the cointegration space is accepted at the $5 \%$ level of significance for the whole sample. We cannot therefore reject the hypothesis that the real exchange rate in Brazil is, again, driven perhaps by a positive demand shock to nontradables. A recursive plot of the cointegration tests of $(1,-1,-1, *)$ with the less restrictive test of $(1,-1, *, *)$ of the last section superimposed is shown for the case of Brazil in Figures 12 and 13. Interestingly, both coefficient restrictions are stable from around 1990 onwards although the increasing instability of the identified cointegration relationship and, visually, the divergence of the two labor series starting in 1995-96 may suggest a scenario similar to that for Mexico.

\section{Conclusion:}

This paper has offered an integrated view of LDC labor market and exchange rate behavior. Modifying the Rogoff-Obstfeld small economy model to include heterogeneous entrepreneurial ability and credit constraints to entering self-employment, it first generates a set of hypotheses about the comovement of relative sector sizes and earnings and the real exchange rate.

These patterns of comovement are then tested in a cointegration framework and we find two provocative results. First, there is strong evidence in favor of the formal and informal sectors being integrated, rather than dual labor markets as customarily envisaged: there is often strong comovement between relative sector sizes and earnings. This offers strong evidence in favor of the dea of viewing informal self employment

primarily as a voluntary non-regulated non-tradable entrepreneurial sector. Much of the 
increase in informality across the 1990s appears explainable by an increase in the relative attractiveness of the sector.

Second, we can explain the appreciations of the peso in Mexico from 1988-1991 and the Brazilian Real from 1993-1996 without recourse to inertial stories. Put differently, in both cases, a positive demand shock to non-tradables appears as a more likely explanation than one based on labor market rigidities. Graphical evidence suggests that similar "equilibrium" phenomena drove the initial appreciations of the Chilean Peso from 1978-1992 and Argentine Peso from 1988-1994. Colombia is the only case where there is evidence of labor market rigidities that may contribute to exchange rate appreciation. That said, in almost all cases, there is a suggestion that, although the initial appreciations were not driven by rigidities, they were nonetheless unsustainable and that the nominal adjustments were eventually required. 


\section{References:}

Agénor, Pierre-Richard and Peter J. Montiel. 1999. "Development macroeconomics." Princeton, N.J.: Princeton University Press.

Aizenman, Joshua and Jacob A. Frenkel. 1988. "Sectorial Wages and the Real Exchange Rate." Journal of International Economics 24:68-91.

Agenor, Pierre-Richard and Joshua Aizenman. (1999). "Macroeconomic Adjustment with Segmented Labor Markets.” Journal of Development Economics 58:277-96.

Aroca, Patricio and William F. Maloney. 1999. "Logit Analysis in a Rotating Panel Context and an Application to Self-Employment Decisions." IBRD Working Paper 2069. Latin America and Caribbean Region, Poverty Reduction and Economic Management Unit, World Bank, Washington D.C. Processed.

Balassa, Bela. 1964. "Trade prospects for developing countries." Yale University. Economic Growth Center. Publications 382, New Haven.

Calvo, Guillermo, 1986, Temporary Stabilizatoin:Predetermined Exchange Rates,’Journal of Political Economy 94:1219-29.

Calvo, Guillermo A. and Carlos A. Vegh, 1993, Exchange Rate Based Stabilizatoin Under Impoerfect Credibility," in Helmut Frisch and Andreas Wortgotter, Open Economy Macroeconomics, London MacMillan, 3-28.

Calvo, Guillermo A. and Carlos A. Vegh, 1994. "Stabilization Dynamics and BackwardLooking Contracts." Journal of Development Economics, v43, n1, February 1994: 59-84.

Cheung, Y.-W. and K.S. Lai. 1993. "Finite sample sizes of Johansen's likelihood ratio tests for cointegration." Oxford Bulletin of Economics and Statistics, 55, 3, 313-328.

Conley, John P and William F. Maloney. 1995. "Optimal sequencing of credible reforms with uncertain outcomes." Journal of Development Economics (NETHERLANDS); 48:151-66.

De Gregorio, Jose, Pablo E. Guidotti and Carlos A. Vegh. 1998. "Inflation Stabilization and the Consumption of Durable Goods." Economic Journal v108, n446 (January 1998): 105-31.

Dorbusch, Rudiger 1982, Stabilization Policies in Developing countries:What Have We learned", World Development 10:701-708.

Dornbusch, Rudiger and Alejandro Werner. 1996. "Mexico, Stabilization, Reform and No Growth (1996)." Brookings Papers in Economic Activity. 
Edwards, Sebastian. 1996. "Exchange Rate Anchors, Credibility and Inertia: A Tale of Two Crises, Chile and Mexico.” American Economic Review, 86,2: 176-180.

Edwards, Sebastian and Alejandra Cox-Edwards. 2000. "Economic reforms and labor markets: policy issues and lessons from Chile." National Bureau of Economic Research. Working Paper Series (U.S.); No. 7646:1-66, Boston, April 2000.

Evans, D.C. and B. Jovanovic. 1989. "An Estimated Model of Entreprenurial Choice under Liquidity Constraints.” Journal of Political Economy 97:4 pp 808-826.

Gil-Diaz, Franciso and Agustin Carstens. 1996. "One Year of Solitude: Some Pilgrim Tales about Mexico’s 1994-1995 Crisis.” American Economic Review, 86,2: 164-169.

Hamilton, Jonathan, Jacques-François Thisse and Yves Zenou. 1998. "Wage Competition with Heterogenous Workers and Firms." Centre for Economic Policy Research. Discussion Paper Series (U.K.); No. 2141:1-22, May 1999.

Helpman, Elhanana and Assaf Razin (1987) Exchange Rate Management: Intetermporal Trade-offs, “ American Economic Review, 77:107-123.

Johansen, Soren. 1988. "Statistical Analysis of Cointegrating Vectors." Journal of Economic Dynamics and Control (Netherlands); 12:231-54 June-September 1988.

Johansen, Soren and Katarina Juselius. 1992. "Testing structural hypothesis in a multivariate cointegration analysis of PPP and UIP for UK." Journal of Econo metrics, 53, 169-209.

Johansen, Soren and Katarina Juselius. 1994. "Identification of the long-run and short-run structure. An application of the ISLM model." Journal of Econometrics, 63, 7-36.

Kravis, Irving B. and Robert E. Lipsey. 1983. "Towards an explanation of National Price Levels." International Finance Section, Department of Economics, Princeton University.

Maloney, W.F. 1999. "Does Informality Imply Segmentation in Urban Labor markets? Evidence from Sectoral Transitions in Mexico." The World Bank Economic Review 13:2 275-302.

1998a. "The Structure of Labor Markets in Developing Countries: Time Series Evidence on Competing Views," IBRD Working Paper 1940, Latin America and the Caribbean Region, Poverty Reduction and Economic Management Unit, World Bank, Washington, D.C. Processed.

1999. "Self-Employment and Labor Turnover: Cross-Country Evidence. The Structure of Labor Markets in Developing Countries: Time Series Evidence on Competing Views." IBRD Working Paper 2102, Latin America and the Caribbean 
Region, Poverty Reduction and Economic Management Unit, World Bank, Washington, D.C. Processed.

1997. "Testing Capital Account Liberalization without Forward Rates: Another look at Chile 1979-1982.” Journal of Development Econo mics, 52:139-168.

Mendoza, Enrique G. and Martin Uribe. 1996. "The Syndrome of Exchange-Rate-Based Stabilizations and the Uncertain Duration of Currency Pegs." Board of Governors of the Federal Reserve System, International Finance Discussion Papers: 548 April 1996 Working Paper.

Obstfeld, Maurice and Kenneth Rogoff. 1996. "Foundations of International Macroeconomics.” Massachusetts Institute of Technology, Boston.

Rebelo, Sergio and Carlos A. Vegh. 1995. "Real Effects of Exchange-Rate-Based Stabilization: An Analysis of Competing Theories." National Bureau of Economic Research macroeconomics annual: 125-74. Cambridge and London: MIT Press.

Rodriguez, Carlos Alfredo, 1982 “The Aregentine Stabilization Program of December $20^{\text {th }}$, World development 10:801-811.

Roldos, Jorge E. 1997. "On Gradual Disinflation, the Real Exchange Rate, and the Current Account.” Journal of International Money and Finance v16, n1 (February 1997): $37-54$

1994. "Supply-Side Effects of Disinflation Programs." International Monetary Fund Working Paper: WP/94/84 July 1994.

Schmidt-Hebbel, K. 1988. "Consumo e inversion en Chile (1974-1983): Una interpretacion 'real' del boom" in F. Morande and K. Schmidt-Hebbel, eds., "Del Auge a la Crisis de 1982." Instituto Interamericano de Mercado de Capital, Santiago.

Taylor, Lance. 1979. “Macro Models for Developing Countries.” New York.

Uribe, Martin. 1997. "Exchange-Rate-Based Inflation Stabilization: The Initial Real Effects of Credible Plans." Journal of Monetary Economics v39, n2, July 1997: 197-221.

Talvi, Ernesto. 1997. "Exchange Rate-Based Stabilization with Endogenous Fiscal Response." Journal of Development Economics v54, n1 (October 1997): 59-75. 


\section{Appendix A: Migration Timing}

Because we assume that the self-employed individual, who is willing to move to the wage-work sector, has to disinstall the capital she borrowed before moving, migration occurs whenever,

$$
\begin{aligned}
& p_{t} A_{n, t} \phi_{j} k_{N, t}^{\alpha_{N}}-\frac{\chi}{2} \frac{\left(I_{j, t}^{2}\right)}{h\left(k_{j, t}\right)}-r k_{n, t}+\sum_{s=t+1}^{\infty}\left(\frac{1}{1+r}\right)^{s-t}\left[p_{s} A_{n, s} \phi_{j} k_{N, s}^{\alpha_{N}}-\frac{\chi}{2} \frac{\left(I_{j, s}^{2}\right)}{h\left(k_{j, s}\right)}-r k_{n, s}\right] \\
& \leq p_{t} A_{n, t} \phi_{j} k_{N, t}^{\alpha_{N}}-\frac{\chi}{2} \frac{\left(-k_{j, t}\right)^{2}}{h\left(k_{j, t}\right)}-r k_{n, t}+\sum_{s=t+1}^{\infty}\left(\frac{1}{1+r}\right)^{s-t} w_{T, s}
\end{aligned}
$$

Labor could adjust within the first period following the shock. However, because individuals are non homogenous when producing in the informal sector, the optimal time for leaving the latter may differ across workers.

The Left Hand Side of the above expression is increasing with entrepreneurial ability. Namely, more able individuals earn more than less able ones. Then the opportunity cost of migrating to the formal sector at time $t$, without considering the direct migration costs corresponding to capital disinstallation, is increasing in the level of entrepreneurial capability. The last term of the RHS, which represents the present value of labor earnings in the formal sector is identical for all individuals at time t. However, the first term of the RHS is likely to be different. The sign of the partial derivative of the latter with respect to $\phi^{j}$ is given by

$$
1-\frac{\chi}{2\left(1-\alpha_{N}\right)} \frac{\alpha_{N}}{r}\left[\frac{\left(a+k_{j}\right)^{2}-a^{2}}{\left(a+k_{j}\right)^{2}}\right]
$$

If the above expression appears to be positive, that would imply that the cost of migrating to the formal sector at time is increasing with the level of entrepreneurial capability. If this is the case, then the total cost of migration is unambiguously increasing with $\phi^{j}$. As a consequence we may expect more able entrepreneurs to postpone their migration towards the wage sector with respect to less able ones.

In the case of a shock leading to an expansion of the informal sector, migration can occur within the first period following the shock, even though capital accumulation may take more than a period because of installation costs. Individuals migrate at the end of period $s$ whenever 
$w_{T, t}-\chi\left(\frac{k_{j, t+1}^{2}}{h(0)}\right)+\sum_{s=t+1}^{\infty}\left(\frac{1}{1+r}\right)^{s-t}\left[p_{s} A_{n, s} \phi_{j} k_{N, s}^{\alpha_{N}}-\frac{\chi}{2} \frac{\left(I_{j, s}^{2}\right)}{h\left(k_{j, s}\right)}-r k_{n, s}\right] \geq w_{T, t}+\sum_{s=t+1}^{\infty}\left(\frac{1}{1+r}\right)^{s-t} w_{T, s}$

Following arguments similar to those presented above, we can infer that more able entrepreneurs will leave the formal sector first, in order to "cash in" the expected earnings differential the soonest. 


\section{Appendix B: The Multivariate Cointegration Analysis of Johans en}

The Johansen procedure allows us to test for cointegration in a multivariate system./ Starting from an unrestricted vector autoregressive model (VAR), the hypothesis of cointegration is formulated as a hypothesis of reduced rank of the long run impact matrix $\Pi$ (Johansen, 1988, Johansen and Juselius, 1990). The VAR is generated by the vector $\mathrm{z}_{\mathrm{t}}$, which defines the potential endogenous variables of the model. Taking first differences of the variables, the VAR can be transformed into an error correction model

$$
\Delta \mathrm{z}_{\mathrm{t}}=\Gamma_{1} \Delta \mathrm{z}_{\mathrm{t}-1}+\ldots+\Gamma_{\mathrm{k}-1} \Delta \mathrm{z}_{\mathrm{t}-\mathrm{k}=1}+\Pi \mathrm{z}_{\mathrm{t}-\mathrm{k}}+\psi \mathrm{D}_{\mathrm{t}}+\varepsilon_{\mathrm{t}}, \quad \varepsilon_{\mathrm{t}} \sim \mathrm{IN}(0, \Sigma)
$$

where the estimates of $\Gamma_{i}=-\left(I-A_{1}-\ldots-A_{i}\right),(i=1, \ldots, k-1)$ describe the short run dynamics to changes in $z$ and $\Pi=-\left(I-A_{1}-\ldots-A_{i}\right)$ captures the long run adjustments and $D$ contains deterministic terms.

Cointegration occurs in the case of reduced rank of $\Pi$. Only if the rank is reduced $(\mathrm{r}<\mathrm{n})$ is it possible to factorize $\Pi$ into $\Pi\left(=\alpha \beta^{\prime}\right)$ where $\alpha$ denotes the adjustment coefficients and $\beta$ the cointegration vectors. The cointegration vectors $\beta$ have the property that $\beta^{\prime} z_{t}$ is stationary even though $z_{t}$ itself is non-stationary.

If the rank is reduced it is possible to interpret the VAR in first differences as a vector error correction model and to obtain estimates of $\alpha$ and $\beta$ via the reduced rank regression. Since the rank of $\Pi$ is equal to the number of independent cointegration vectors and the rank of $\Pi$ is also equal to the number of non-zero eigenvalues, the test of cointegration thus amounts to a test for the number of non-zero eigenvalues. The trace statistics, $\lambda_{\text {trace }}$, is a non-standard distributed likelihood-ratio test, which is commonly used to determine the number of cointegration vectors, (Johansen, 1988). The trace statistic tests the null hypothesis that there are at most $r$ cointegration vectors:

$$
H_{0}: \lambda_{i}=0, \text { for } \mathrm{i}=\mathrm{r}+1, . . \mathrm{n}
$$

where only the first $r$ eigenvalues, $\lambda$, are non-zero against the unrestricted hypothesis that $r=n .{ }^{16}$

${ }^{16}$ The null hypothesis of at most $r$ cointegration vectors implies that there are $n-r$ unit roots and, theoretically, $n-r$ zero eigenvalues. This is because the hypothesis of cointegration is formulated as the reduced rank of $\Pi=\alpha \beta^{\prime}$ and the full rank of $\alpha_{\perp}{ }^{\prime} \Gamma \beta_{\perp}$, where $\alpha$ and $\beta$ are $n \times r$ matrices and $\alpha_{\perp}$ and 
It is now common practice to try to identify the cointegration space and we follow the approach outlined in Johansen (1992) and Johansen and Juselius (1994). In their approach, a system is exactly or just identified if $k=r-1$ restrictions are placed on each cointegration vector and the rank condition for generic identification is satisfied. ${ }^{17}$

$\beta_{\perp}$ are $\mathrm{n} \times(n-r)$ matrices orthogonal to $\alpha$ and $\beta$. This allows us then to distinguish between $r$ cointegrating $\mathrm{I}(0)$ relations and $\mathrm{n}-r$ non-cointegrating $\mathrm{I}(1)$ relations.

${ }^{17}$ In the case of two cointegration vectors generic identification requires that the rank condition $\operatorname{rank}\left(R_{i}^{\prime} H_{j}\right) \geq 1$ for $i, j=1,2$ and $i \neq j$ is fulfilled. Where $R_{i}$ is the orthogonal complement of $H_{i}$, such that $R_{i}$ and $H_{i}$ are both of full rank and satisfy the conditions $R_{i}{ }^{\prime} H_{i}=0, R_{i}{ }^{\prime} \beta_{\mathrm{i}}=0$ and $\beta_{\mathrm{i}}=H_{i} \varphi_{\mathrm{i}} . R_{i}$ are $p * k$ matrices and $H_{i}$ are $p * s$ matrices with $k+s=p$. 
Table 1

\begin{tabular}{|c|c|c|c|c|c|}
\hline $\begin{array}{c}\text { Short / } \\
\text { Medium Run }\end{array}$ & & & $\Delta\left(w_{T} / w_{N}\right)$ & $\Delta\left(L_{T} / L_{N}\right)$ & $\Delta p$ \\
\hline \multirow{3}{*}{ Flexible Wage } & $\Delta A_{T}>0$ & & $>0$ & $>0$ & $>0$ \\
\hline & $\Delta A_{N}>0$ & & $<0$ & $<0$ & $\begin{array}{c}<0 \\
\text { (undersh.) }\end{array}$ \\
\hline & $\Delta \gamma<0$ & & $<0$ & $<0$ & $\begin{array}{c}0> \\
\text { (oversh.) }\end{array}$ \\
\hline \multirow[t]{2}{*}{ Wage Rigidities } & \multirow[t]{2}{*}{$\Delta A_{T}<0$} & $\theta>A$ & $>0$ & $<0$ & $<0$ \\
\hline & & $\theta<A$ & $<0$ & $<0$ & $<0,>0$ \\
\hline \multicolumn{6}{|l|}{ Long Run } \\
\hline \multirow{3}{*}{ Flexible Wage } & $\Delta A_{T}>0$ & & $>0$ & $>0$ & $>0$ \\
\hline & $\Delta A_{N}>0$ & & $<0$ & $<0$ & $<0$ \\
\hline & $\Delta \gamma<0$ & & $<0$ & $<0$ & 0 \\
\hline \multirow[t]{2}{*}{ Wage Rigidities } & \multirow[t]{2}{*}{$\Delta A_{T}<0$} & $\theta>A$ & $>0$ & $<0$ & $<0$ \\
\hline & & $\theta<A$ & $<0$ & $<0$ & $<0$ \\
\hline$A=\frac{\varphi_{s e}-\gamma}{\gamma}$ & & & & & \\
\hline
\end{tabular}


Table 2

\begin{tabular}{|c|c|c|c|c|c|c|}
\hline & & Mexico & Brazil & Colombia & & \\
\hline Null & Alternative & Lag: 4 & Lag: 4 & Lag: 2 & $95 \%$ & $90 \%$ \\
\hline Hypothesis & Hypothesis & With Constant & With Constant & With Constant & Critical Value & Critical Value \\
\hline \multicolumn{7}{|l|}{$\lambda_{\text {trace }}$ test } \\
\hline$r=0$ & $r>0$ & $55.80^{*}$ & $40.56^{*}$ & $36.45^{*}$ & 35.10 & 31.88 \\
\hline $\mathrm{r} \leq 1$ & $r>1$ & 12.08 & 19.68 & 6.43 & 20.17 & 17.79 \\
\hline$r \leq 2$ & $r>2$ & 4.04 & 6.05 & 1.69 & 9.10 & 7.50 \\
\hline
\end{tabular}

${ }^{*}$ Rejection at the $5 \%$ level of significance ${ }^{18}$

Table 3

\begin{tabular}{lccc}
\hline & Mexico & Brazil & Colombia \\
\hline & $\beta$ & $\beta$ & $\beta$ \\
$\mathrm{n}_{\mathrm{T}} / \mathrm{n}_{\mathrm{N}}$ & 1.000 & 1.000 & 1.000 \\
$\mathrm{~W}_{\mathrm{T}} / \mathrm{W}_{\mathrm{N}}$ & 0.969 & -0.637 & 2.846 \\
$\mathrm{P}$ & 0.976 & -0.356 & -2.776 \\
Constant & -2.803 & 0.101 & -4.811 \\
\hline
\end{tabular}

Table 4

\begin{tabular}{l|c|c|c|c|c|c}
\hline \multicolumn{3}{l|}{} & \multicolumn{3}{l|}{ México } & \multicolumn{2}{l|}{ Brazil } & \multicolumn{2}{l}{ Colombia } \\
& $\alpha$ & t-stat. & $\alpha$ & t-stat. & $\alpha$ & t-stat. \\
$\Delta \mathrm{n}_{\mathrm{T}} / \mathrm{n}_{\mathrm{N}}$ & 0.028 & 0.531 & -0.012 & -0.212 & -0.213 & -1.750 \\
$\Delta \mathrm{W}_{\mathrm{T}} / \mathrm{W}_{\mathrm{N}}$ & -0.088 & -3.393 & 0.572 & 3.841 & -0.057 & -1.961 \\
$\Delta \mathrm{p}$ & -0.250 & -6.457 & 0.281 & 2.381 & 0.088 & 6.009 \\
\hline
\end{tabular}

Note: $\Delta$ indicates a variable in first differences.

Table 5: Summary of Hypothesis Tests (whole sample)

\begin{tabular}{llll}
\hline & Mexico & Brazil & Colombia \\
\hline Integrated & $\chi^{2}(1)=15.42$ & $\chi^{2}(1)=1.87$ & $\chi^{2}(1)=16.96$ \\
$(\mathbf{1}, \mathbf{- 1}, * * *)$ & $\mathrm{p}=0.00$ & $\mathrm{p}=0.17$ & $\mathrm{p}=0.00$ \\
Segmented & $\chi^{2}(1)=0.04$ & $\chi^{2}(1)=7.26$ & $\chi^{2}(1)=5.13$ \\
$(\mathbf{1}, \mathbf{1}, *, *)$ & $\mathrm{p}=0.84$ & $\mathrm{p}=0.01$ & $\mathrm{p}=0.02$ \\
\hline
\end{tabular}

Table 6: Test of $(1,-1,-1, *)$ being part of the cointegration space in different subsamples

\begin{tabular}{lll}
\hline & México & Brazil \\
\hline Sample: & 1988:01- 1993:04: & 1982:01- 1998:02: \\
& $\chi^{2}(2)=4.35, \mathrm{p}=0.11$ & $\chi^{2}(2)=5.06, \mathrm{p}=0.08$ \\
\hline
\end{tabular}

\footnotetext{
${ }^{18}$ The Reinsel-Ahn small sample corrected critical value at the $10 \%$ level is 43.13 for Mexico, 39.53 for Brazil and 36.32 for Colombia).
} 
Figure 1:
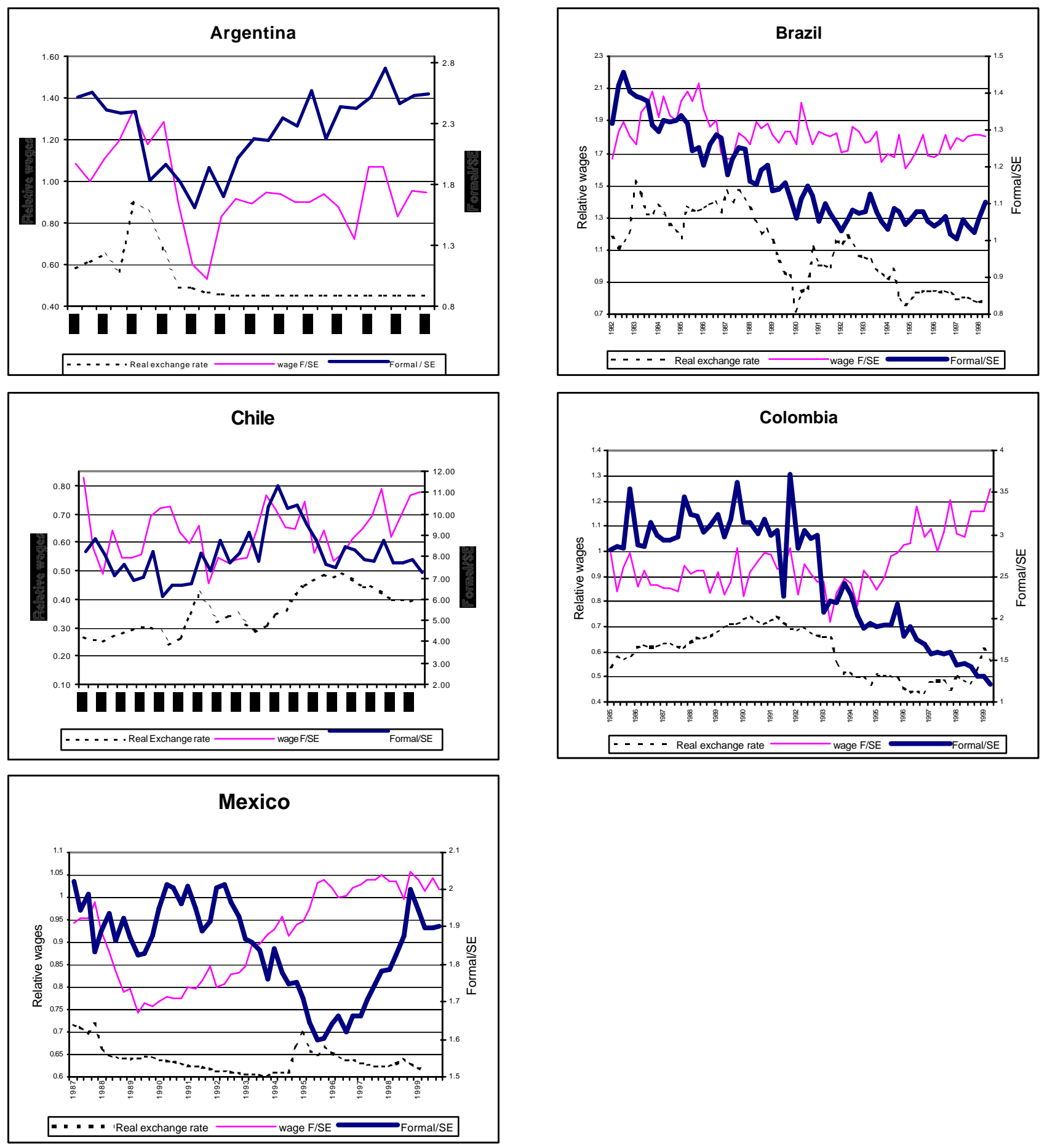
Figure 2: Self-employment and gradual capital adjustment

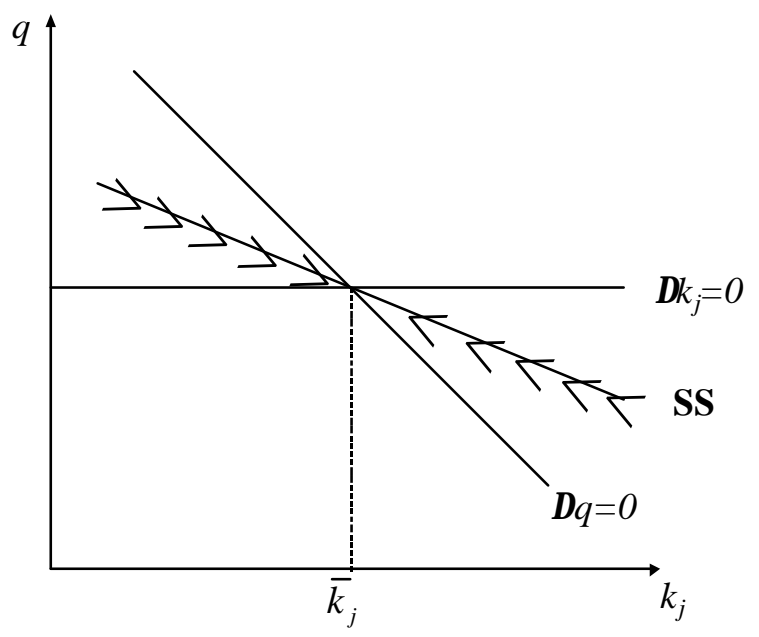

Figure 3: Capital decumulation for migrating self-employed

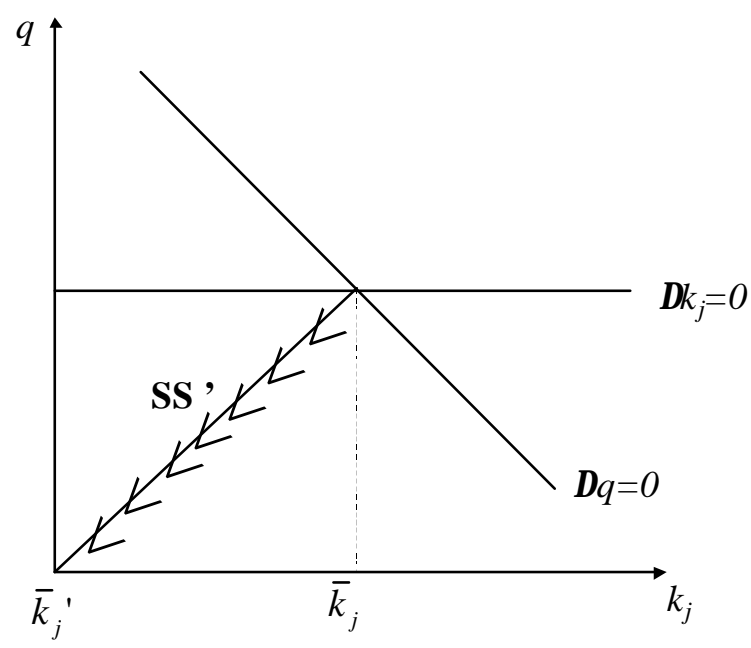


Negative co-movements of relative wages and sector sizes

Figure 4: Mexico

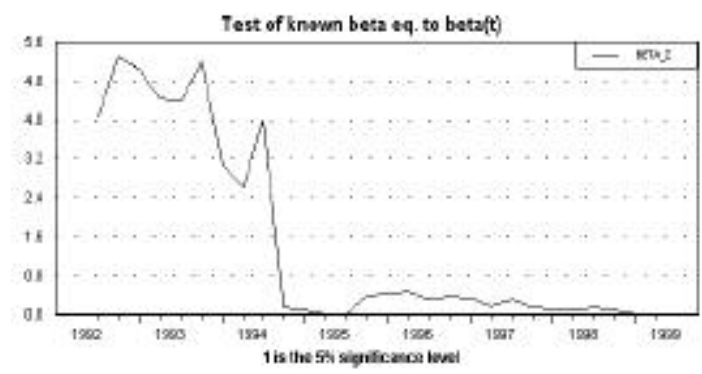

Figure 6: Mexico - alternative base period

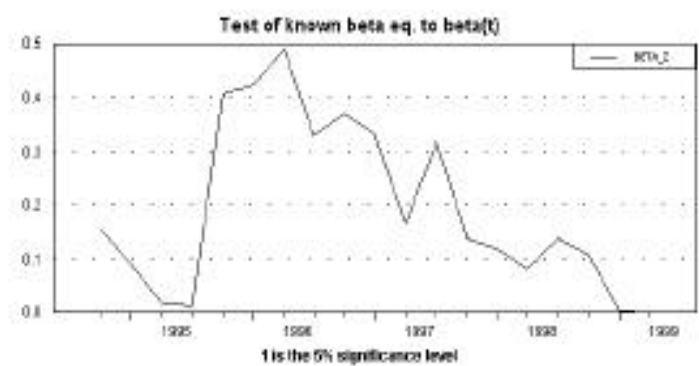

Figure 8: Brazil

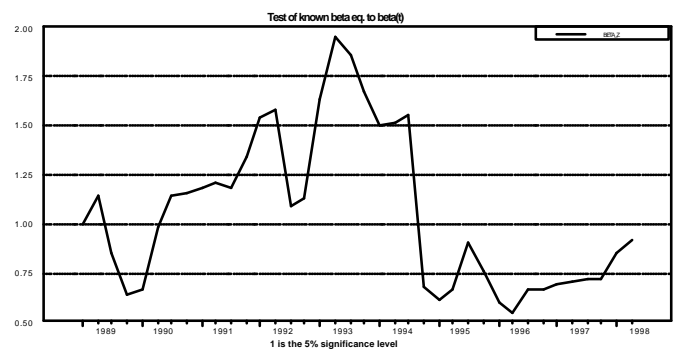

Figure 10: Colombia

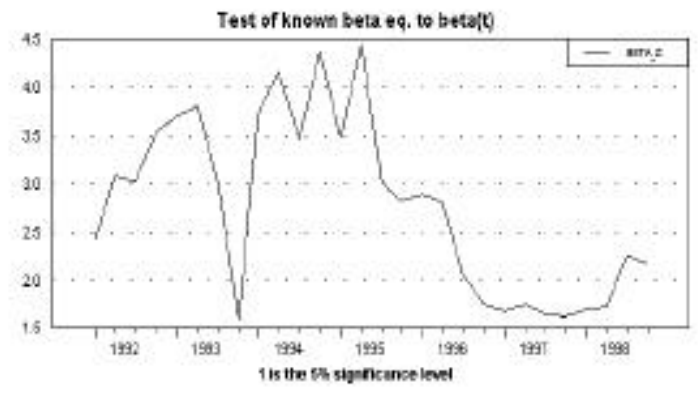

Positive co-movements of relative wages and sector sizes

Figure 5: Mexico

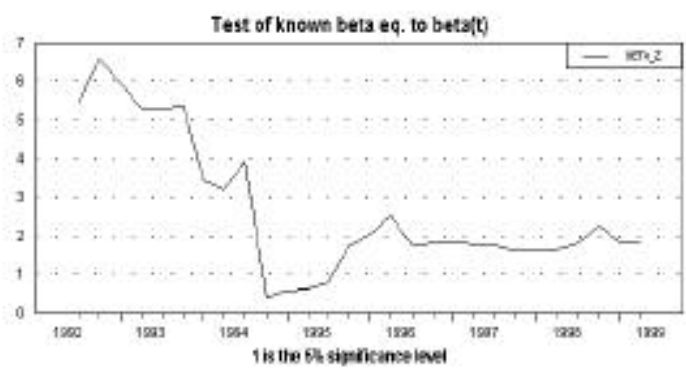

Figure 7: Mexico - alternative base period

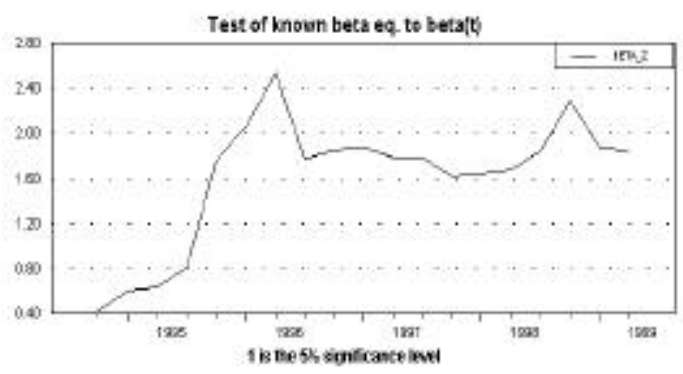

Figure 9: Brazil

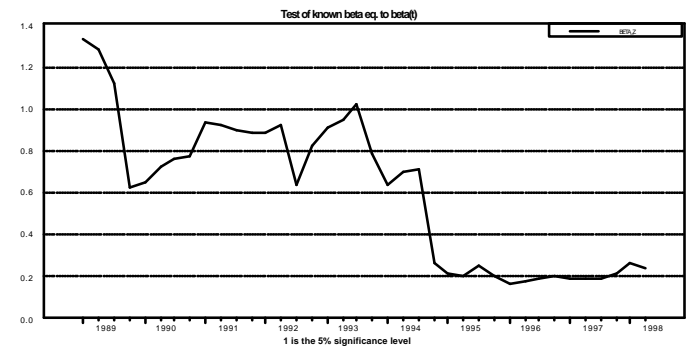

Figure 11: Colombia

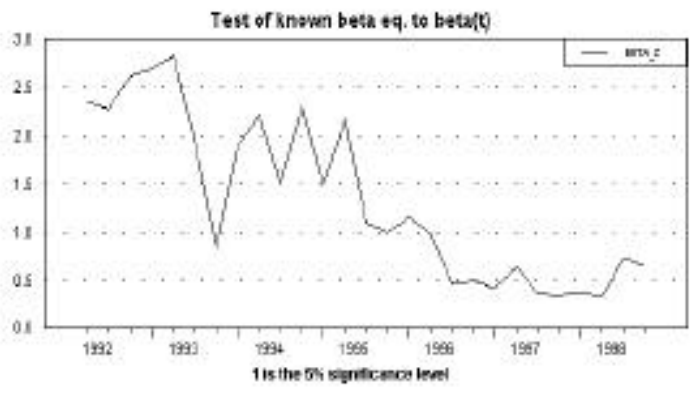


Figure 12: Brazil $(1,-1, *, *)$ versus $(1,-1,-1, *)$ restrictions

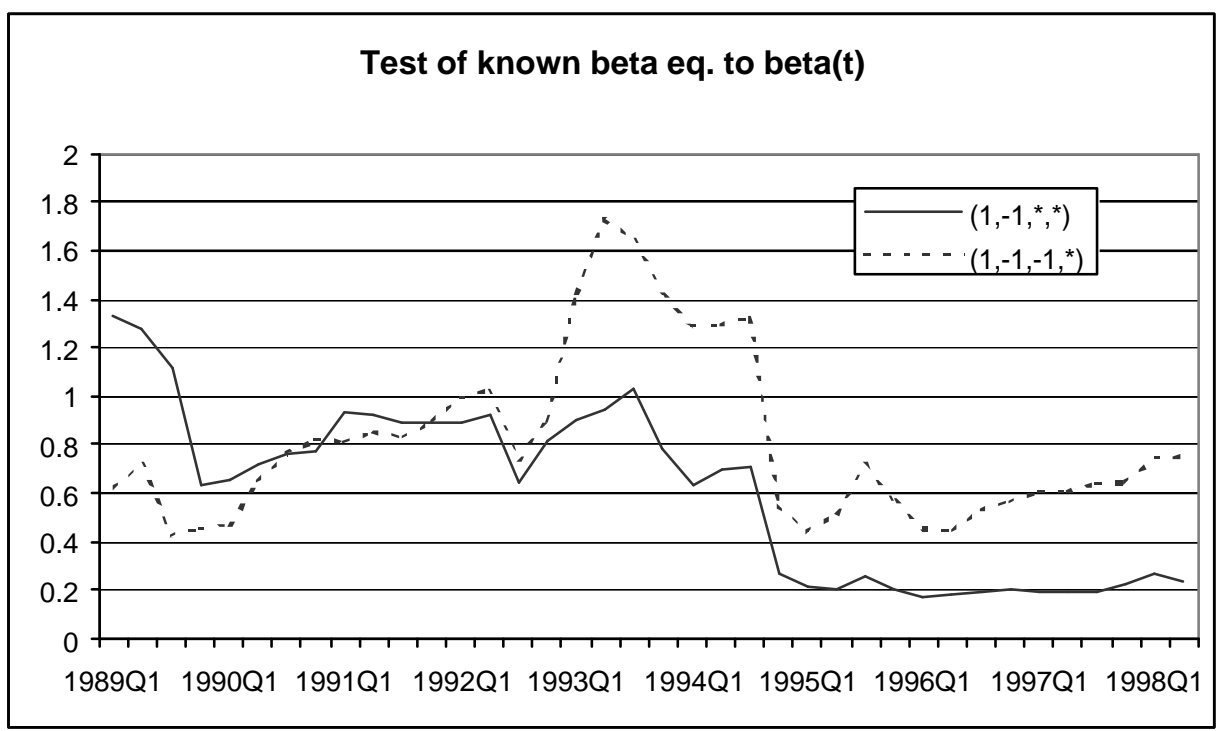

Figure 13: Brazil $(1,-1, *, *)$ versus $(1,-1,-1, *)$ restrictions [without dummies]

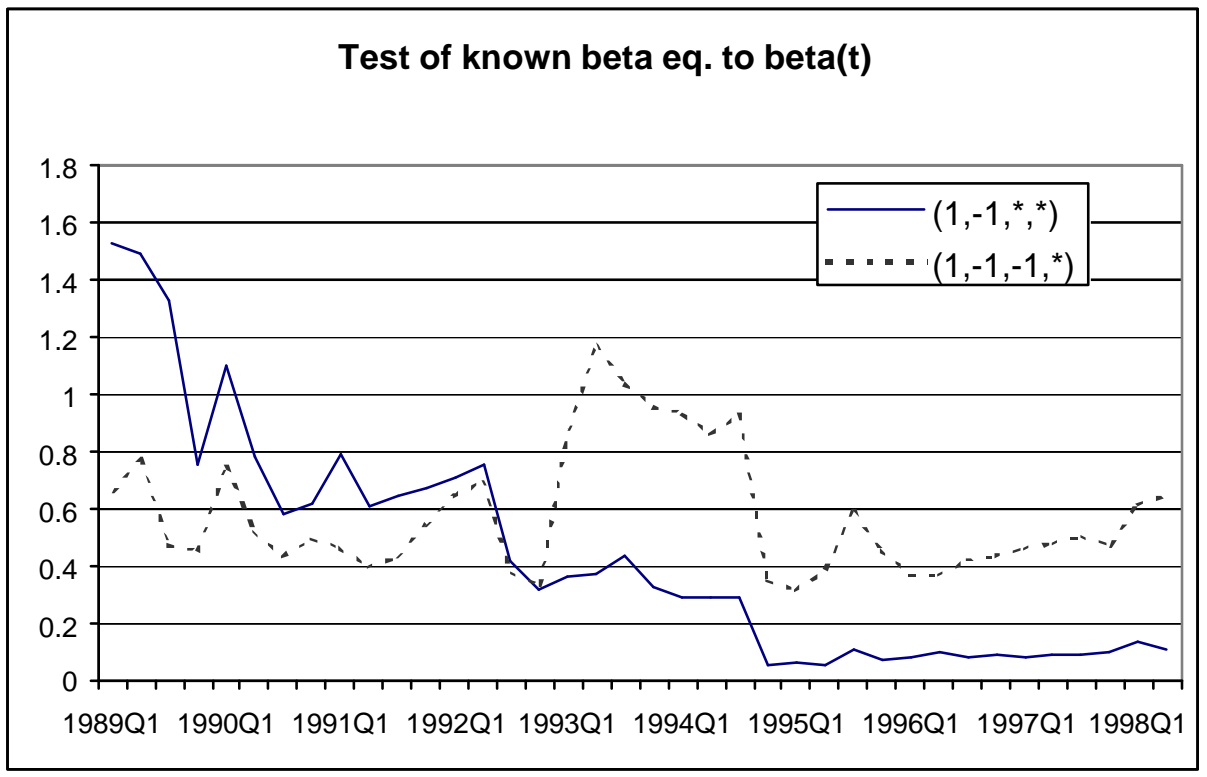

Note: Difference between Figures 12 and 13 is that underlying model in Figure 13 is without dummies. Since critical values of the Johansen test are not strictly valid in the presence of dummies, this is a common sensitivity analysis. 
Figure 14: Mexico: Recursive Trace Test:

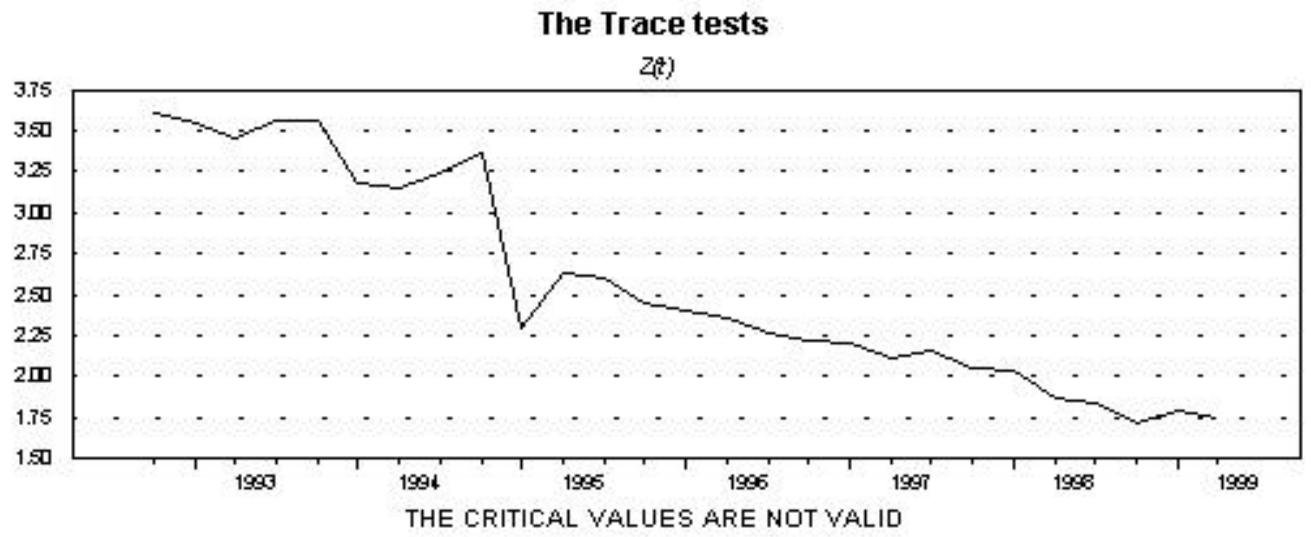

Figure 15 : Brazil: Recursive Trace Test:

The Trace tests

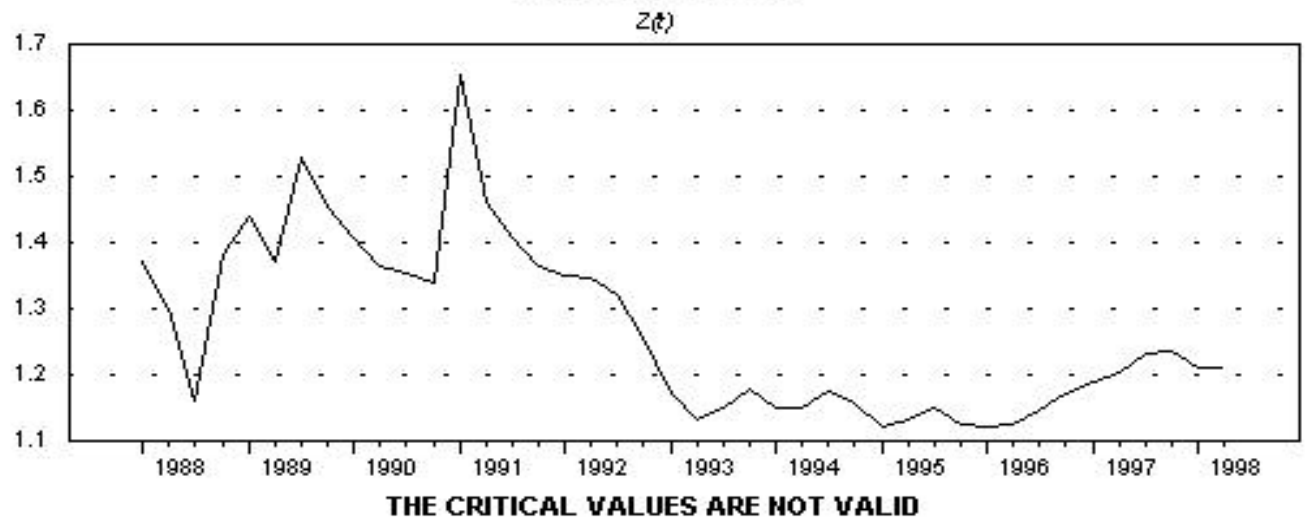

Figure 16: Colombia: Recursive Trace Test:

The Trace tests

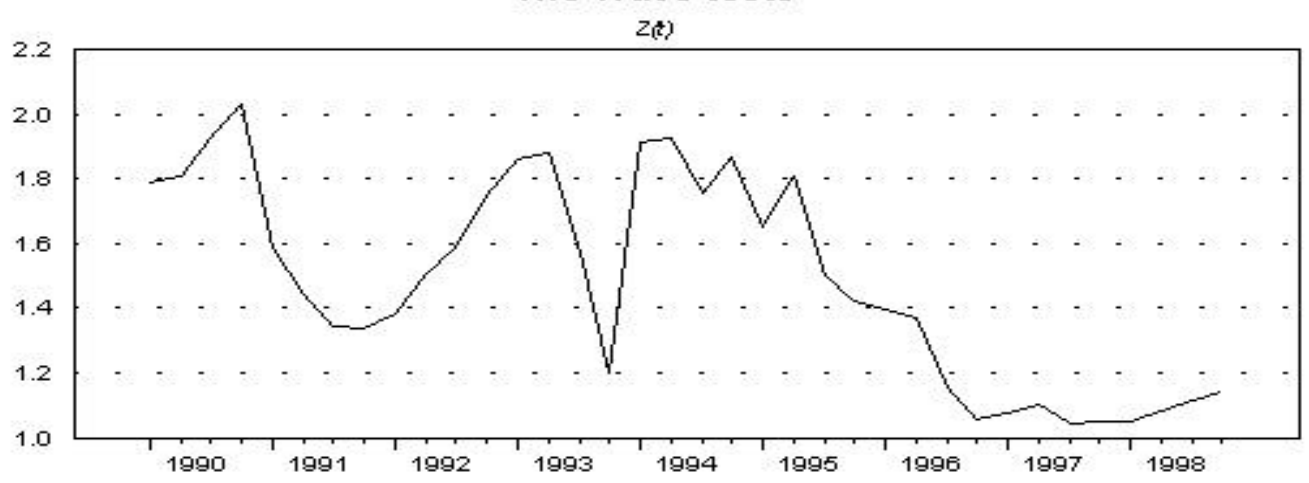


Model Specification Tests for the VAR models:

Table 7: Tests for Long-Run Exclusion, Stationarity and Weak Exogeneity

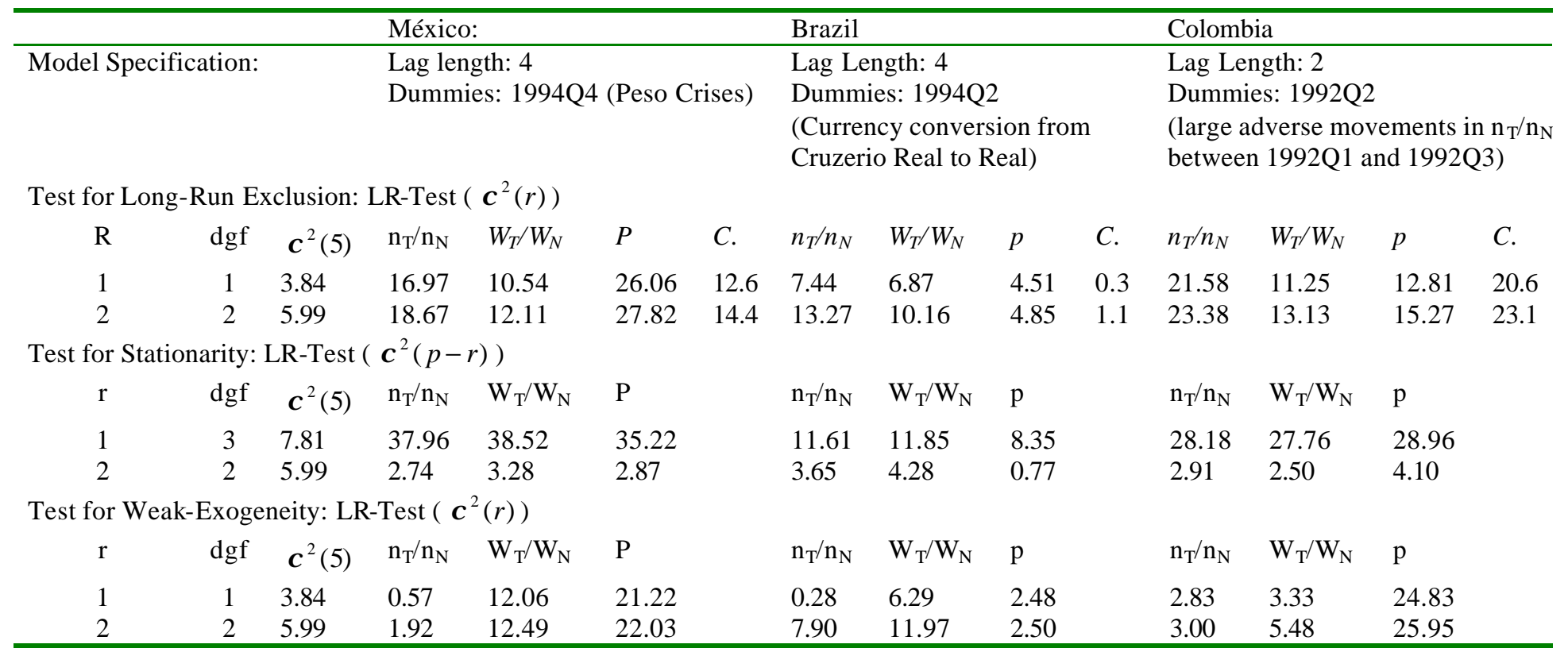

Table 8: Multivariate Statistics (Residual Analysis)

\begin{tabular}{l|l|l|l}
\hline & México: & Brazil & Colombia \\
\hline Information Criteria: & -15.90 & -15.40 & -13.37 \\
SC & -16.95 & -16.21 & -13.85 \\
HQ & & & \\
Autocorrelation & $\chi^{2}(63)=74.3, \mathrm{p}$-value $=0.16$ & $\chi^{2}(11)=140.8, \mathrm{p}$-val. $=0.01$ & $\chi^{2}(99)=129.5, \mathrm{p}$-value $=0.02$ \\
Ljung-Box: & $\chi^{2}(9)=7.09, \mathrm{p}$-value $=0.63$ & $\chi^{2}(9)=16.9, \mathrm{p}$-value $=0.05$ & $\chi^{2}(9)=7.6, \mathrm{p}$-value $=0.58$ \\
$\mathrm{LM}(1)$ & $\chi^{2}(9)=9.7, \mathrm{p}$-value $=0.38$ & $\chi^{2}(9)=4.4, \mathrm{p}$-value $=0.88$ & $\chi^{2}(9)=7.9, \mathrm{p}$-value $=0.54$ \\
$\mathrm{LM}(4)$ & $\chi^{2}(6)=9.14, \mathrm{p}$-value $=0.17$ & $\chi^{2}(6)=10.1, \mathrm{p}$-value $=0.12$ & $\chi^{2}(6)=31.5, \mathrm{p}$-value $=0.00$ \\
Normality & & &
\end{tabular}

Table 9: Univariate Test Statistics (Residual Analysis)

\begin{tabular}{l|cll|llll|lll}
\hline & Mexico & & & Brazil & & & \multicolumn{3}{c}{ Colombia } \\
\hline & $\mathrm{n}_{\mathrm{T}} / \mathrm{n}_{\mathrm{N}}$ & $\mathrm{W}_{\mathrm{T}} / \mathrm{W}_{\mathrm{N}}$ & $\mathrm{p}$ & $\mathrm{n}_{\mathrm{T}} / \mathrm{n}_{\mathrm{N}}$ & $\mathrm{W}_{\mathrm{T}} / \mathrm{W}_{\mathrm{N}}$ & $\mathrm{p}$ & $\mathrm{n}_{\mathrm{T}} / \mathrm{n}_{\mathrm{N}}$ & $\mathrm{W}_{\mathrm{T}} / \mathrm{W}_{\mathrm{N}}$ & $\mathrm{p}$ \\
Skewness & 0.8483 & -0.4627 & 0.0814 & -0.3984 & 0.1036 & 0.7109 & 0.2750 & -0.1402 & -0.014 \\
Kurtosis & 4.1049 & 3.3300 & 3.2463 & 2.6781 & 2.2688 & 3.4843 & 5.8000 & 4.3100 & 3.8161 \\
ARCH & 2.4730 & 0.8230 & 9.9090 & 11.1260 & 1.2360 & 2.9560 & 4.3170 & 2.7780 & 3.3060 \\
Normality & 5.7730 & 2.2730 & 1.4720 & 2.4550 & 1.2400 & 5.6900 & 19.6240 & 7.6740 & 4.4030 \\
$R^{2}$ & 0.2330 & 0.5250 & 0.8130 & 0.3760 & 0.4470 & 0.4980 & 0.4050 & 0.3840 & 0.4110 \\
\hline
\end{tabular}


